$41(3) \mid 2012$

Recomposiciones territoriales de las periferias de las metrópolis andinas

\title{
Las periferias, ¿territorios de incertidumbre? El caso de Pachacútec, Lima-Callao, Perú
}

Les périphéries, territoires de l'incertitude? Le cas de Pachacútec, Lima-Callao, Pérou

The peripheries, territories of uncertainty? The case of Pachacutec in Lima-

Callao, Peru

\section{Alexis Sierra y Daniel Ortiz}

\section{(2) OpenEdition \\ Journals}

\section{Edición electrónica}

URL: http://journals.openedition.org/bifea/400

DOI: 10.4000/bifea.400

ISSN: 2076-5827

Editor

Institut Français d'Études Andines

Edición impresa

Fecha de publicación: 31 diciembre 2012

Paginación: 523-554

ISSN: 0303-7495

Referencia electrónica

Alexis Sierra y Daniel Ortiz, « Las periferias, ¿territorios de incertidumbre? El caso de Pachacútec,

Lima-Callao, Perú », Bulletin de l'Institut français d'études andines [En línea], 41 (3) | 2012, Publicado el 01 agosto 2013, consultado el 05 noviembre 2020. URL : http://journals.openedition.org/bifea/400 ; DOI : https://doi.org/10.4000/bifea.400

\section{BY NO ND}

Les contenus du Bulletin de l'Institut français d'études andines sont mis à disposition selon les termes de la licence Creative Commons Attribution - Pas d'Utilisation Commerciale - Pas de Modification 4.0 International. 


\title{
Las periferias, iterritorios de incertidumbre? El caso de Pachacútec, Lima-Callao, Perú
}

\author{
Alexis Sierra* \\ Daniel Ortiz*
}

Resumen

Pachacútec es una margen urbana, periférica de la aglomeración Lima/Callao, cuyo desarrollo es históricamente marcado por numerosas incertidumbres. Pensar un manejo de emergencia vinculada a un sismo de gran magnitud puede sustentarse en base al estudio del origen de esta margen, la cual es similar a una emergencia, y al estudio de las formas de ciudadanía que se desarrollan. La informalidad, que justifica la estigmatización del territorio, puede verse como un recurso para reducir la incertidumbre, tanto en la vida cotidiana como en la emergencia. Sin embargo, son las tensiones en torno al control territorial que nutren la incertidumbre la más problemática y que imponen una reflexión sobre la autonomía como respuesta para el desarrollo.

Palabras claves: control territorial, incertidumbre, informalidad, margen urbana, Lima

\section{Les périphéries, territoires de l'incertitude ? Le cas de Pachacútec, Lima-Callao, Pérou}

\section{Résumé}

Pachacútec est une marge urbaine, périphérique de l'agglomération de Lima/Callao, historiquement marquée par de nombreuses incertitudes quant à son développement. L'étude de sa genèse, apparentée à une forme de crise, est un moyen de penser une éventuelle gestion de crise liée à un séisme de

* Geógrafo, Instituto de Investigación para el Desarrollo (IRD), c/ Teruel 357, Miraflores, Lima 18, programa PACIVUR y INVERSES (www.inverses.org). E-mail: alexisierra2001@yahoo.fr

** Geógrafo, Universidad Nacional Mayor de San Marcos (UNMSM), facultad de geografía, Av. Universitaria /Av. Germán Amézaga s/n., Cercado de Lima - Lima 1. E-mail: ortizsdaniel@gmail.com 
grande magnitude. L'informalité, qui stigmatise ce territoire peut ainsi être considérée comme une ressource pour réduire l'incertitude tant au quotidien qu'en cas de crise. Cependant, c'est le contrôle territorial qui représente la plus grande source $d^{\prime}$ incertitude du fait de pouvoirs parallèles. Les formes d'autonomie élaborées en réponse au mal développement et aux situations de forte incertitude sont alors soumises aux rapports de force entre les différents acteurs en présence.

Mots clés : contrôle territorial, incertitude, informalité, marge urbaine, Lima

\title{
The peripheries, territories of uncertainty? The case of Pachacutec in Lima-Callao, Peru
}

\begin{abstract}
Pachacútec is a marginal area, on the periphery of the Lima/Callao agglomeration, that has been marked by an uncertain, erratic development over time. Thinking through the future management of an emergency resulting from an earthquake of great magnitude can be based on the study of the origin of this marginal area. The informality, which stigmatises this area, can be considered as a resource to reduce uncertainty in everyday life as well as in case of crisis. However, the tensions surrounding territorial control represents the largest source of uncertainty. This demands reflection on the impact of autonomy as a strategy for development.
\end{abstract}

Key Words: Territorial control, uncertainty, informality, marginal area, Lima

La globalización contemporánea se caracteriza por una incertidumbre generalizada (Ghorra-Gobin, 2006): una crisis en un punto del globo tiene consecuencias en varias partes del mundo sin que todos los efectos del impacto inicial puedan ser previstos y estas incertidumbres valen a todas las escalas de las autoridades a los individuos. Es lo propio del riesgo sistémico, término usado primero en las finanzas, el cual se articula con preferencia en el mundo actual a las metrópolis, urbes conectadas al «archipiélago metropolitano mundial» (Dolfuss, 1997). Las metrópolis concentran población, bienes, actividades, capitales, informaciones, decisiones que influyen sobre el territorio nacional al cual pertenecen y funcionan como nodos en la red que constituyen con otras ciudades del mundo. Por lo tanto, son consideradas como lugares mayores y claves de la globalización y del mundo, es decir caracterizados por un alto grado de «mundialidad», usando la palabra del geógrafo Denis Retaillé. De este modo, una perturbación en una de ellas tiene consecuencias diferenciadas en los otros lugares y territorios del mundo. Un sismo en una de ellas a pesar de ser una amenaza claramente identificada tiene consecuencias y perspectivas de manejo muy inciertas, teniendo además en cuenta la heterogeneidad interna de estas metrópolis.

En efecto, si estas metrópolis funcionan como lugares, puntos y nodos del mundo contemporáneo, son también, cambiando de escala, territorios heterogéneos complejos, difíciles de manejar por la concentración de población, de actores, de 
actividades, de bienes, todos interconectados entre sí y con los otros territorios metropolitanos. A esta misma escala, un impacto en una parte de la urbe puede tener efectos para toda la metrópoli y, de ahí, según el rango y el rol de la ciudad, tener consecuencias en el resto del país o de una región del mundo. Por lo tanto, la heterogeneidad y la fragmentación del territorio metropolitano constituyen una fuente de incertidumbre en las consecuencias de un desastre y en el manejo de una emergencia. No todos los territorios de la metrópoli tienen el mismo rol en el desarrollo o la difusión de una crisis. Esto depende de la concentración de actores, de servicios y de actividades, en particular de concentraciones de recursos necesarios para el funcionamento de la ciudad. De este modo, la incertidumbre sobre el impacto de un evento tiene un componente espacial clave. Por tener un dinamismo particular y por la falta de conocimiento que se tiene de los nuevos territorios urbanos más recientemente creados, las periferias conllevan una mayor incertidumbre en cuanto a su capacidad de respuesta y a su rol en la difusión de la crisis.

De las múltiples periferias que existen, las que nos interesan en este estudio son las que corresponden a márgenes urbanas, en el sentido de espacios sometidos a una situación de rechazo, procedente de percepciones oficiales y mayoritarias, con situaciones muchas veces transitorias e indefinidas (Sierra \& Tadié, 2008). El conocimiento de tales márgenes por parte del resto de la ciudad es débil, propicio a desarollar diferentes representaciones muchas veces negativas y por lo tanto, consideradas como inciertas frente a una emergencia.

Dos tipos de incertidumbres nos interesan en particular: la primera es relativa a los recursos con los cuales puede contar la población para enfrentar una emergencia. Nuestro enfoque se basa en la metodología desarrollada a nivel metropolitano por el proyecto Sirad (2011) sustentada en la confrontación de tres espacialidades de crisis: el espacio vulnerable considerado el afectado, el espacio de peligro y el espacio de recursos que contempla todos los elementos esenciales para manejar una emergencia (D'Ercole \& Metzger, 2009). Se trató de aplicar esta metodología a la escala de un territorio periférico. Si bien una serie de recursos del funcionamento de la metrópoli son pensados para toda la ciudad, algunos pueden ser específicos a las márgenes urbanas y ayudar a su gestión autónoma, por lo menos en las primeras horas después del desastre. Estos recursos tienen un fuerte componente de informalidad. Por lo tanto, uno de nuestros planteamientos será considerar el rol de la informalidad como fuente de incertidumbre $y$, al mismo tiempo, como respuesta a la incertidumbre en tiempo de emergencia. La segunda incertidumbre tiene que ver con el control territorial. Uno de los temores que existen en cuanto a la ocurrencia de un desastre es el desorden que puede ocasionar, visión catastrófica generada por las imágenes vinculadas a saqueos como en Chile (Rojo, 2010) y la afirmación de poderes informales, alternos a la autoridad pública. Por lo tanto, el tema del control territorial es clave: las tensiones existentes sobre el control de una margen urbana como Pachacútec, son a la vez una incertidumbre cotidiana con consecuencias en la manera de vivir en la ciudad y representan una vulnerabilidad en el manejo de una crisis con la cual hay que contar. La ausencia de autoridad pública y de instituciones estatales deja lugar a 
otros tipos de actores que pueden añadir, o al revés, reducir las incertidumbres en caso de emergencia. Es uno de los puntos que trataremos de esclarecer.

Por lo tanto, nuestra perspectiva inicial de una crisis de toda la metrópoli no tiene que dejar de lado el hecho de que la primera incertidumbre para la población es la gestión de lo cotidiano, y no la gestión vinculada a un riesgo preciso de origen natural. Es clave subrayar que definimos el riesgo no tanto por la existencia de un peligro, factor necesario, sino por la existencia de intereses y desafíos para el funcionamento y desarrollo de la ciudad, y que el riesgo depende de la confrontación de percepciones que dan lugar a una representación mayoritaria de lo que es clave guardar, conservar, desarrollar. De este modo, el riesgo se define por lo que se puede perder, lo que está en juego, ya sea por un sismo o una bomba (Sierra, 2000; 2009). Este artículo plantea la problématica de una articulación entre la incertidumbre como perspectiva cotidiana y la incertidumbre vinculada al impacto de un evento excepcional, dentro de un marco conceptual y de una problemática que sigue la lógica desarrollada inicialmente en Quito a partir de 1996, y actualmente nutrida dentro de los programas de investigación PACIVUR 1 e INVERSES2.

¿Qué consecuencias puede tener una crisis sobre las márgenes urbanas de una metrópoli? ¿Qué capacidades tienen esos territorios frente a la incertidumbre del manejo de una emergencia? ¿Cómo la incertidumbre que vive su población en lo cotidiano influye sobre el impacto de una crisis?

El caso de Lima es ejemplar. Metrópoli de 9,3 millones de habitantes3, extendida sobre más de $2800 \mathrm{~km}^{2}$, la capital peruana constituye un territorio particularmente fragmentado, dividido en dos regiones (Lima Metropolitana y Callao) y 49 distritos con gran autonomía. Esta metrópoli está particularmente expuesta a un sismo de gran magnitud. Los sismos de Pisco en 2007 y de Concepción (Chile) en 2010 han puesto sobre la agenda pública el riesgo de desastre vinculado a la ocurrencia de un sismo. Dada la extensión de Lima y el mosaico territorial que reprensenta, un sismo de tal magnitud agravaría las rupturas territoriales existentes, y hasta generaría nuevas. En particular, las periferias norte y de las vertientes concentran los asentamientos humanos, lotizaciones informales, autoconstrucciones que carecen de servicios. Por tales características, se les considera como espacios vulnerables. Dentro de ellos, elegimos a Pachacútec, la «última megabarriada del siglo XX» (Matos Mar, 2012). Esta margen urbana del norte de la aglomeración fue nuestro campo de estudio para identificar a cuáles incertidumbres tendría que enfrentarse la población y las autoridades en caso de emergencia. Para tal objetivo, hicimos un trabajo de campo con entrevistas o encuestas a diferentes actores (dirigentes barriales, responsables de organizaciones sociales, dirigentes de mercados, representantes de la municipalidad, responsable del ordenamiento

1 Programa Andino de Capacitación y de Investigación sobre Vulnerabilidad Urbana y Riesgos, iniciado por Robert D’Ercole y el IRD en 2006, en Quito, Lima y La Paz.

2 Informalité, Pouvoirs et Envers des Espaces Urbains, programa iniciado en 2011 con financiamiento de la Municipalidad de París, comparando ocho ciudades del mundo (www.inverses.org).

3 Proyecciones del INEI. 
inicial, policía, mototaxis, transportistas) y vecinos en general. En paralelo hicimos varias observaciones directas y georreferenciaciones en el transcurso del año 2011. Procesamos los datos para poder elaborar mapas y realizar el análisis espacial, político y social.

Este trabajo de campo permitió primero relacionar la difícil accesibilidad y la situación de periferia de Pachacútec con la perspectiva de un manejo autónomo de la emergencia. En segundo lugar, veremos sobre cuáles recursos de gestión de crisis, tanto formales como informales, puede contar esta margen urbana. Al final, trataremos de articular la problemática del control territorial con la de la incertidumbre vinculada a la gestión del riesgo de desastre.

\section{PACHACÚTEC, UNA PERIFERIA LIMEÑA Y UN CONFÍN REGIONAL}

La Ciudadela Pachacútec o Pachacútec es un territorio ubicado en la periferia norte de Lima (fig. 1), siendo uno de los confines de la mancha urbana. A esta situación de confín morfológico, se añade un confín político-administrativo. Pachacútec se ubica en el límite norte del distrito chalaco ${ }^{4}$ de Ventanilla colindando con el distrito limeño de Santa Rosa. De este modo, este asentamiento se ubica en un límite entre dos distritos que es de igual manera límite de dos provincias-regiones, Lima Metropolitana y la provincia constitucional del Callao5. Esta ubicación es de gran relevancia. Por una parte, significa el alejamiento de los centros políticos y administrativos tanto nacional como regional, provincial e incluso distrital. Por otra parte, representa un factor de incertidumbre sobre el manejo de una emergencia: ¿quién va a intervenir en estos territorios periféricos: los grupos de intervención del Callao, o los de distritos de la provincia de Lima de la cual no dependen, pero que pueden estar más cerca? Esta pregunta es pertinente debido a que existe una mayor intensidad de vínculos externos de la población de Pachacútec con Puente Piedra y Lima, que con el Callao como lo veremos más adelante.

\section{1. Una creación política en respuesta a una crisis del alojamiento}

La población actual es recién llegada en este confín territorial y el resultado de la populista política peruana de vivienda. Los primeros vecinos se instalaron en esta pampa desértica compuesta de arenales en 1988, cuando el presidente Alan García en su primer mandato decidió abrir una lotización, llamada Proyecto especial Ciudad Pachacútec6. Sin embargo, su desarollo se estancó durante más de diez

4 Chalaco: de Callao.

5 El Perú está divido en departamentos que son las grandes divisiones regionales administrativas del país. Los gobiernos regionales recién creados están al frente de estos departamentos a excepción de Lima. En este caso, el departamento de Lima está divido en tres provincias: Lima provincias, Lima metropolitana y Callao. Los territorios de Lima Metropolitana y del Callao son de esta forma a la vez los de la provincia y de la región.

6 Decreto Supremo n. ${ }^{\circ}$ 010-88-VC, del 4 de julio de 1988. 


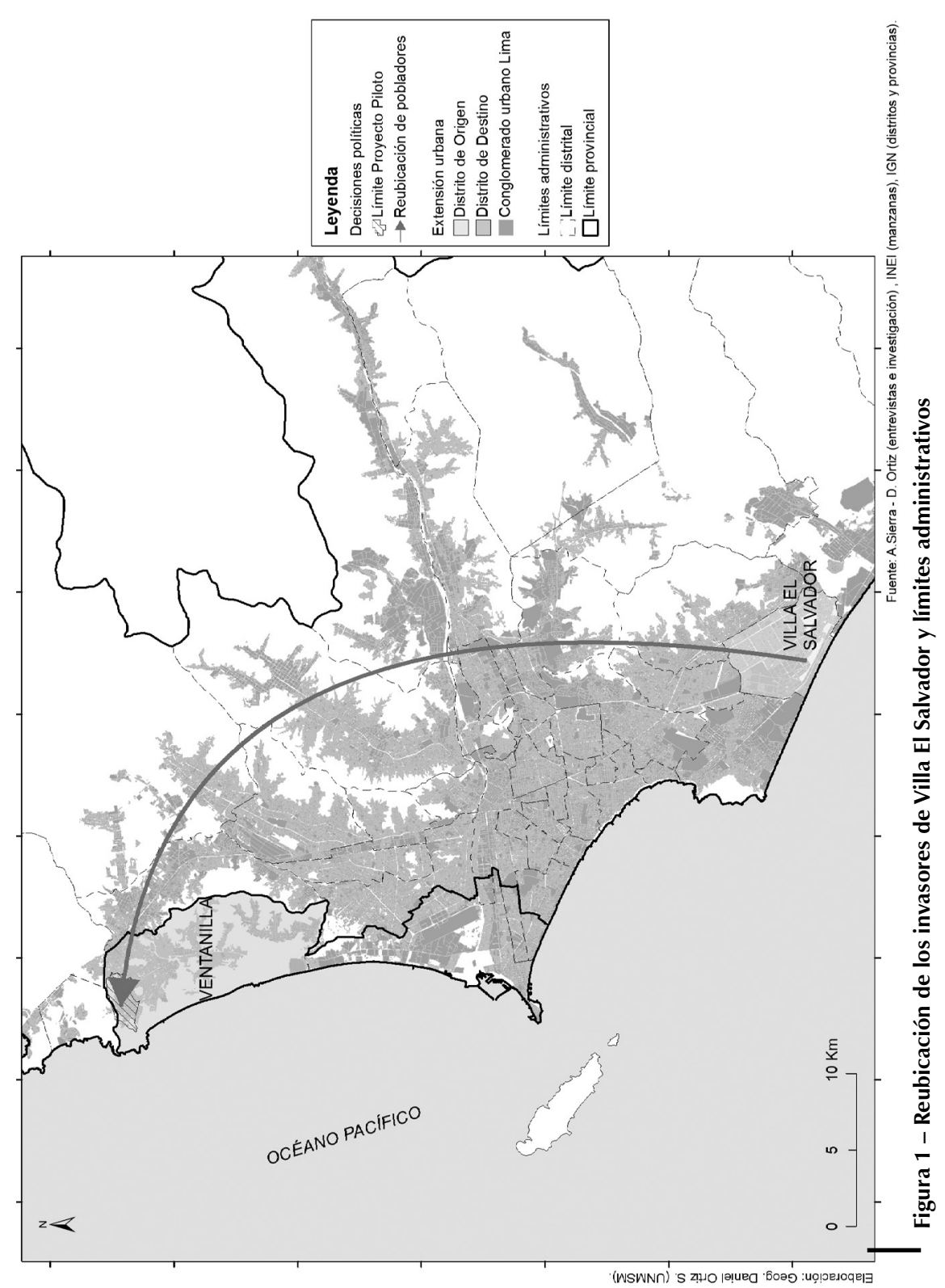


años. Todo el poblado se estableció en este arenal periférico a partir de inicios del año 2000. En aquel entonces, el presidente Fujimori, ya en periodo pre-electoral, decide la reubicación de miles de invasores del distrito sureño de Villa El Salvador (CIMAD, 2005; Matos Mar, 2012)7. Ellos habían invadido terrenos privados lo que provocó enfrentamientos violentos. Pachacútec estaba conformado por terrenos del Estado por lo cual se decidió transferir a la población allá, sin otros bienes que los que llevaban encima. Con la movilización de las Fuerzas Armadas y de la Policía Nacional fueron más de ocho mil las personas que fueron trasladadas del Sur al Norte, de una periferia a otra, la segunda siendo todavía más alejada del centro que la primera (28 km contra $21 \mathrm{~km}$ ) (fig. 1). A esta población, en el mismo momento de la mudanza, se añadieron otros vecinos en búsqueda de una tierra para construir su vivienda. Este evento de fundación urbana repentina constituye la historia épica y un elemento de identidad de Pachacútec. Ahora bien, por su rapidez, su masividad y el trastorno que significa, esta mudanza representa en sí misma una emergencia. Por lo tanto, no aclara sobre los recursos y los medios usados en tal caso.

A raíz de esta emergencia, el gobierno crea el Programa de Lote Familiar (Profam) en febrero de 2000 para organizar la creación del asentamiento. Las Fuerzas Armadas abrieron pistas, y Cofopris realizó el primer empadronamiento. Sin embargo faltaban equipamiento y servicios, con los cuales el gobierno se había comprometido. El Pronaa9 asistía a la población con alimentos y Sedapal (la empresa de agua del Estado) con agua, ambos de manera provisional. A mediados de 2000, las obras no arrancaban. Solo se realizaron empadronamientos y Profam creó módulos educativos, de salud, mercados, comités de vaso de leche, wawa wasi10 y comedores populares de emergencia (CIMAD, 2005). Esta historia pone así de relieve el rol que se les da a las organizaciones sociales en un contexto de carencia de servicios públicos y cierta forma de asistencialismo del Estado. En el contexto de transición entre el fin del periodo fujimorista y el restablecimiento de la democracia, la urbanización sigue sin política de mejoramiento por parte del Estado. Sin embargo, sigue la distribución de lotes por parte del Ministerio de Transporte y Comunicaciones que tiene a su cargo la política de vivienda. Debido a la demora de los servicios públicos, la planificación previa contaba con zonas de equipamiento, servicios y espacios públicos que estuvieron en primera instancia, a cargo de la misma población con ayuda de ONG y fondos internacionales. Poco a poco, con la acción de las ONG y de fondos extranjeros, la población realizó ciertos equipamientos. Esta escasez de recursos se añadía al alejamiento y a las difíciles condiciones del sitio por ser un arenal particularmente nebuloso y

7 Entrevista a Mario Palomino, responsable de asentamientos humanos en la gerencia de desarollo urbano del MML, uno de los tres responsables de la distribución de lotes al inicio de Pachacútec (14/04/2012).

8 Organismo estatal creado por A. Fujimori para formalizar y entregar títulos de propiedad individual.

9 Programa Nacional de Asistencia Alimenticia dependiendo desde 2011 del ministerio de Desarrollo e Inclusión Social.

10 Tipo de guardería para niños pre-escolares. 
húmedo en invierno. A tal punto que, a pesar de la falta de vivienda, una parte de los moradores se mudó de nuevo, disminuyendo así la población del asentamiento (Caramutti, 2004). Todo este proceso muestra una inestabilidad fuerte que limita la capacidad de proyectarse y el desarollo de un territorio urbano, aunque por otra parte refuerza el sentimiento comunitario de los que quedaron.

Después del retiro del gobierno central a mediados de 2000 y del segundo empadronamiento, aparecen conflictos entre propietarios y se inicia el tráfico de lotes: familias no vinieron a instalarse de inmediato y traficantes tomaron posesión de los lotes, vacantes pero empadronados, para venderlos a terceros. Demoró la entrega de los títulos de propiedad, producto de la estrategia por parte de las autoridades para consolidar el asentamiento. Luego de unos años, la propiedad de los terrenos no titulados fue traspasada a la región Callao11. Hoy en día existen todavía lotes ocupados, en particular por talleres en la zona industrial, que siguen siendo de propiedad de la Región. Por lo tanto, esta tiene todo el respaldo legal para expulsar esas actividades si estuviera interesada en hacerlo. Es de subrayar que aquí como en todos los asentamientos creados en Lima, la falta de títulos de propiedad es una fuente de incertidumbre: la población teme la posible reubicación, sobre todo cuando aquellos terrenos están zonificados de forma diferente de la vigente de facto y nutre la desconfianza hacia las autoridades. La falta de títulos obstaculiza también la posibilidad de préstamos o la constitución de un patrimonio transmisible. Favorece en el caso de Pachacútec, pero seguramente en otros casos, la presión de traficantes de tierra, y de mafias locales para desalojar a gente que no cumple con sus directivas, quitándole un terreno sin temor a quejas pues la víctima no puede comprobar que le roban un terreno del cual no es propietario.

A pesar de esta situación, el desarrollo imperfecto del proceso de urbanización junto a la necesidad de alojarse, y la organización de la entrega de lotes con cierto grado de formalidad, llevaron a la existencia actual de un poblado urbano de 75000 habitantes. Este se divide en tres zonas: el proyecto especial Ciudad Pachacútec, los Asentamientos Humanos formalizados y el Proyecto Piloto Nuevo Pachacútec que Ilamaremos Nuevo Pachacútec por comodidad. Este último, de más de 30000 habitantes, es el que se analizó más precisamente. Viendo las necesidades de la población y la extensión territorial (531 ha), Nuevo Pachacútec fue divido en cinco sectores A, B, C, D y E con una junta vecinal electa al frente de cada uno de ellos.

Esta historia es reveladora del proceso de desarrollo autónomo y de formas de ciudadanía características de estas periferias, que deben hacer frente a diversos tipos de incertidumbre. Como vimos, la población tuvo que adaptarse a varios ambientes urbanos, mudándose dentro de la aglomeración después de haber, en muchos casos, migrado a Lima12. Tuvo que pelear para obtener lotes, defenderlos y construir sus viviendas. Tuvo que organizarse para tener equipamientos y servicios.

11 Decreto Supremo de la Presidencia de la República D. S. 003-2004-Vivienda publicado el 28 de febrero de 2004.

12 En 2004, las 3/4 partes de la población había nacido en provincia. 
En particular, frente a la emergencia que representó este repentino asentamiento, la primera respuesta fue fundar organizaciones sociales vinculadas a programas nacionales (Vaso de leche, Wawa wasi, comedores populares) y luego de ganar en autonomía, pidiendo la ayuda de ONG.

\section{2. Un alejamiento que favorece la autonomía al resto de la ciudad}

Sin embargo, Pachacútec depende de otros lugares de la metrópoli para ciertos asuntos bien cernidos y principalmente comerciales (fig. 2).

Los mercados locales tienen que abastecerse de alimentos en dos lugares de interés mayor: por una parte, el terminal pesquero ubicado al límite del distrito del Callao y de Ventanilla para el abasto de pescado y mariscos y, por otra parte, los mercados mayoristas de La Parada y los mercados aledaños a estos. La Parada constituye el lugar más alejado para las necesidades colectivas y cotidianas de la población que trata de no ir tan lejos. Por eso, el distrito visitado con mayor frecuencia es el de Puente Piedra.

Este último es un distrito de interés para los moradores, por varias razones, entre las cuales están:

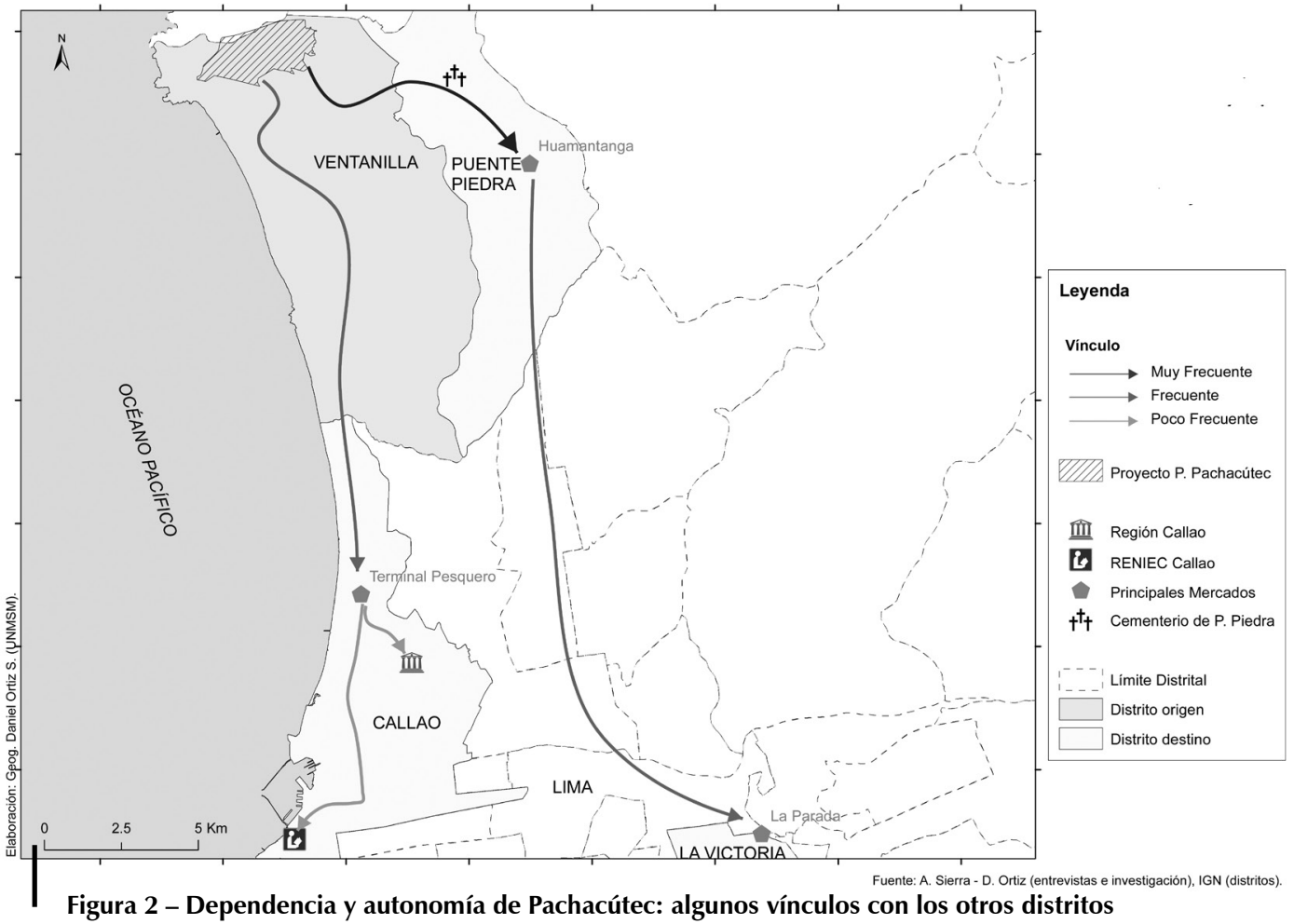


- Para directamente hacer compras (mercado Huamantanga, supermercado Plaza Vea, otros mercados y tiendas).

- Para el ocio.

- Para sepultar a sus muertos, pues el cementerio oficial y más cercano es el de Puente Piedra.

Al contrario, la necesidad de ir al Callao es limitada a algunos asuntos administrativos como el trámite para licencias en la prefectura o en las administraciones regionales y provinciales. Cabe anotar que el distrito de Ventanilla al cual pertenece Pachacútec procede de Puente Piedra13 y fue integrado a la provincia del Callao por decisión del gobierno militar en el 1969. La población de Pachacútec, llegada más tarde, no conoció este antiguo vínculo político-administrativo con Puente Piedra, pero esa decisión política, que tenía como propósito desarrollar el litoral norte del Callao, fue el origen de una fragmentación territorial, creando un nuevo distrito al mismo tiempo que se lo separaba políticamente del poblado más cercano.

Básicamente, dos carreteras unen Pachacútec al resto de la ciudad (fig. 3): la salida a la Panamericana norte que permite ir a Puente Piedra y de ahí al centro

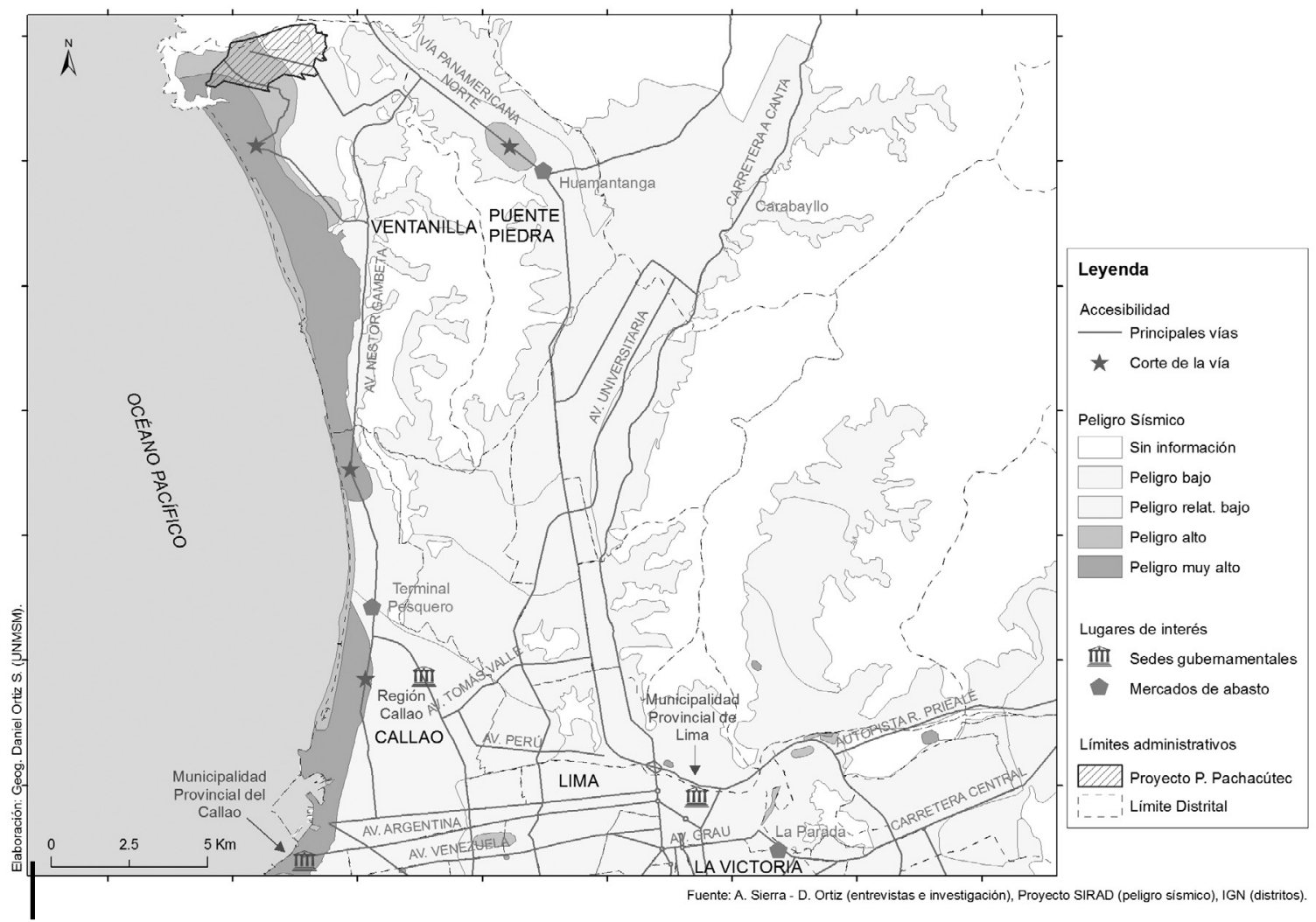

Figura 3 - Peligro sísmico del suelo y posibles cortes de vías

13 Decreto ley 17392 del 28 de enero de 1969. 
de Lima, y la carretera costera que pasa por los humedales y se prolonga por la Av. Néstor Gambetta que va de Ventanilla al Callao. De día, tres líneas de transporte público usan esas carreteras a partir de Pachacútec (fig. 4): dos, de las cuales la de mayor capacidad (línea 41), pasan por la Panamericana norte. La tercera pasa por la costa y ni siquiera permite ir directamente al centro del Callao pues se desvía hacia el centro de Lima. Esto muestra aún más la autonomía de Pachacútec con respecto a su región. Estos vínculos limitados se reducen aún de noche y de madrugada (figs. 5 y 6). A partir de las 21 h, ya no funciona la ruta a la costa (la que además pasa por el centro de Ventanilla). Y a partir de las $22 \mathrm{~h}$, solo sirven taxis colectivos para ir a Puente Piedra (y no a Ventanilla).

Esta situación muestra la debilidad de los lazos de Pachacútec con el resto de la metrópoli y más que todo de la región, provincia e incluso del distrito a los cuales pertenece. En otros términos, Pachacútec vive ya de forma bastante aislada. Aunque la población necesite trabajar afuera y la producción de los tallares de Pachacútec sea vendida en el centro de Lima, el poblado se organiza de forma bastante autónoma. Se puede plantear la hipótesis que esta autonomía de facto sea reforzada por la ocurrencia de un sismo de gran magnitud. En efecto, la probabilidad de que las dos carreteras de acceso a Pachacútec estén cortadas es fuerte, aislando aún más Pachacútec del resto de la ciudad (fig. 3). Es tomando en

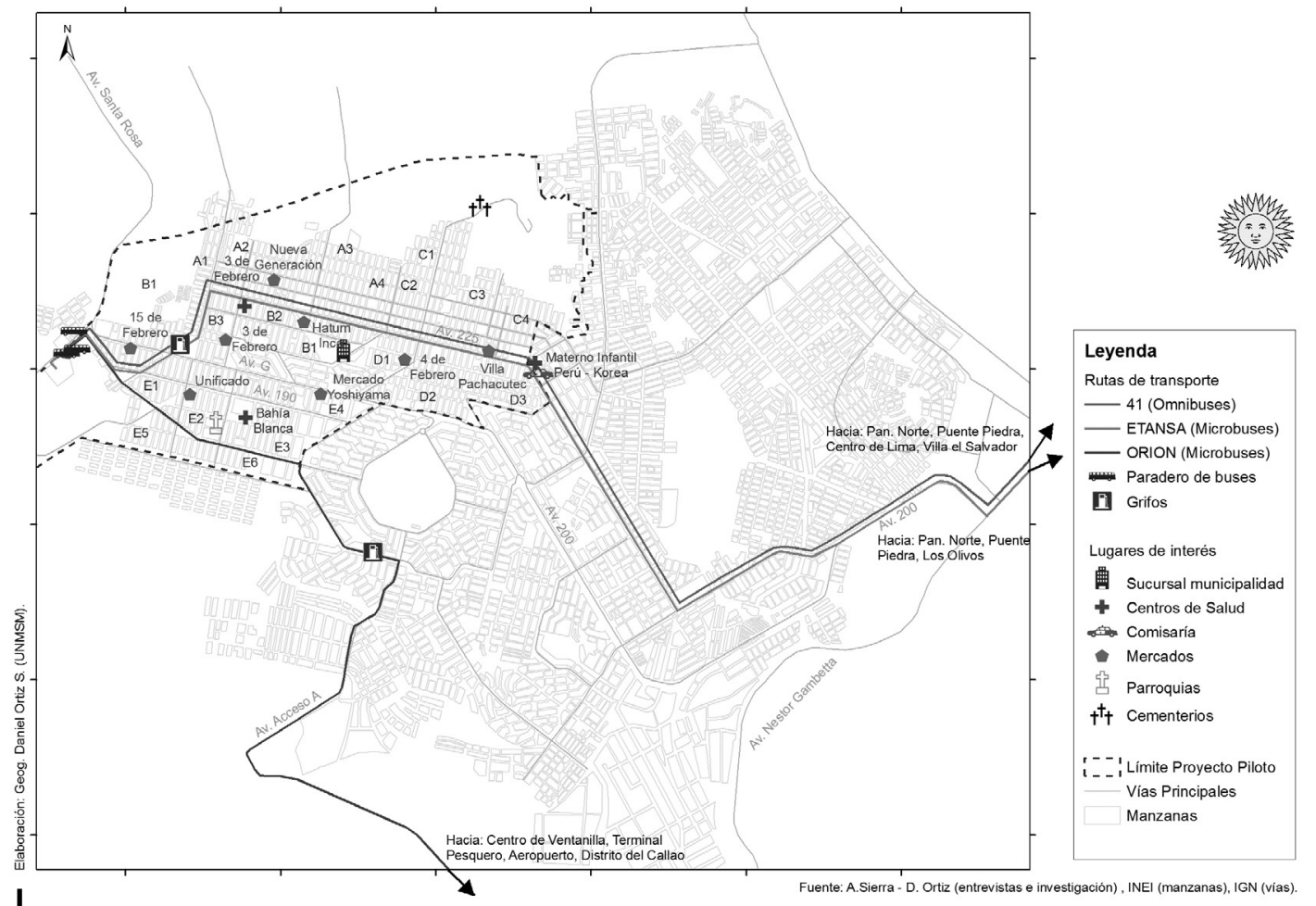

Figura 4 - Transporte público durante el día (4:30 a. m. - 9:00 p.m.) 


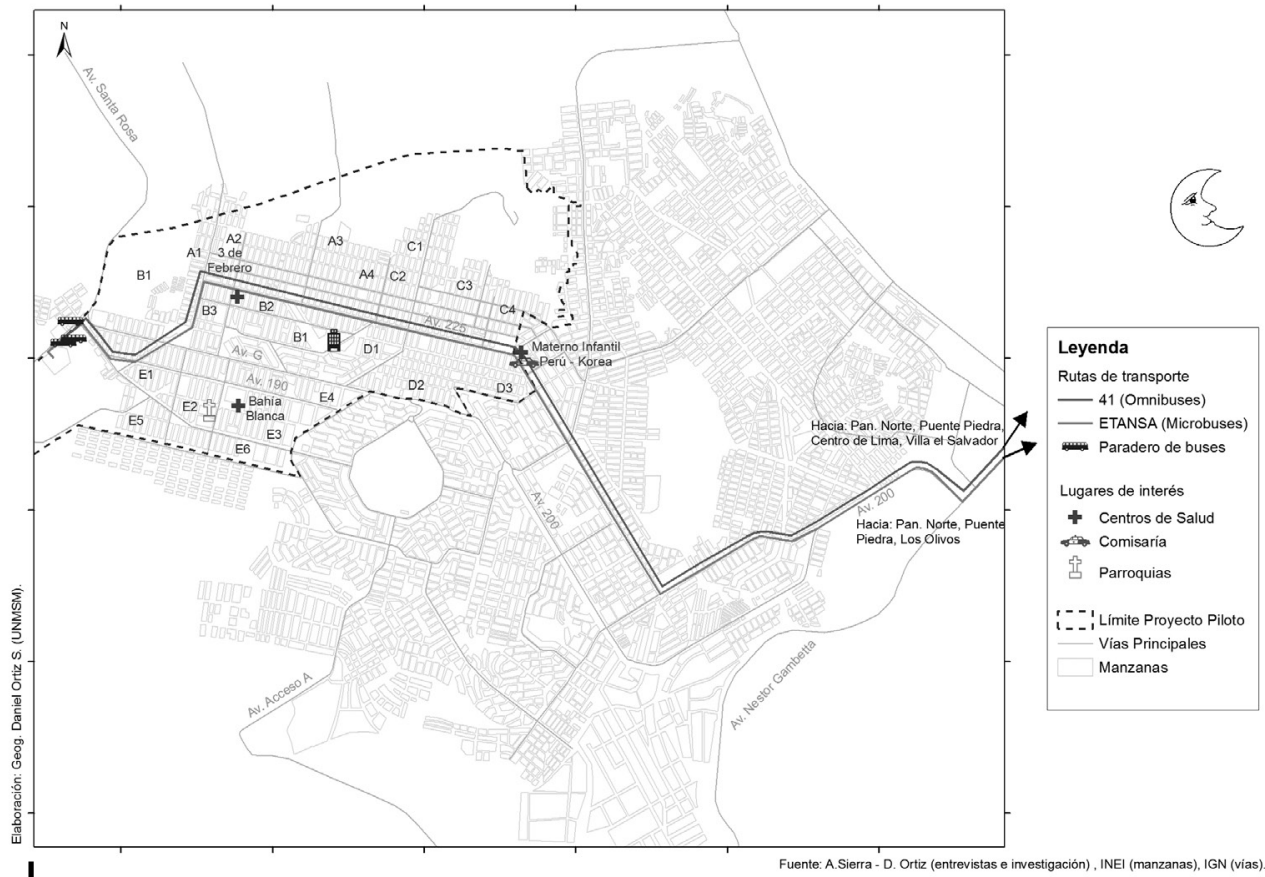

Figura 5 - Transporte público durante la noche (9:00 p.m. - 10:00 p.m.)

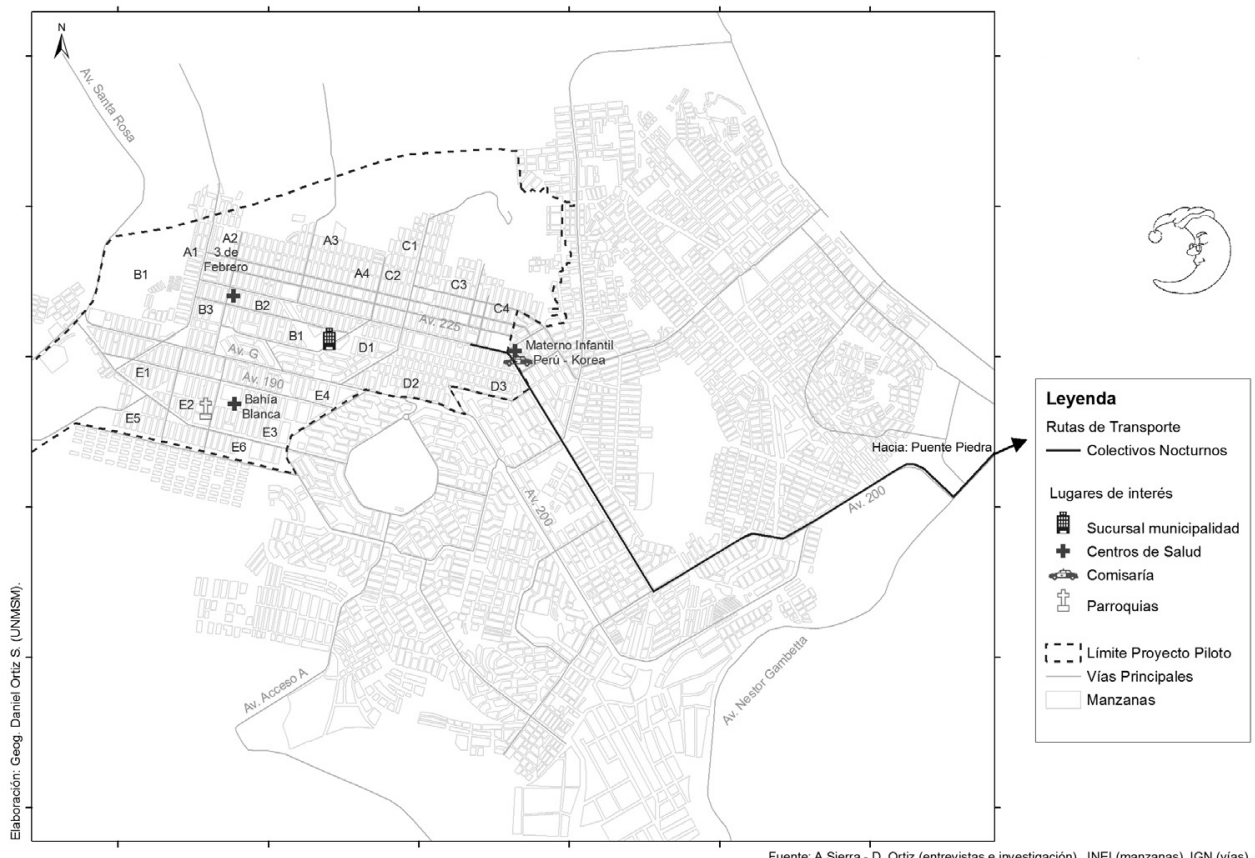

Figura 6 - Transporte público durante la madrugada (10:00 p.m. - 4:30 a.m.) 
cuenta esta posible situación que intentamos reflexionar sobre el manejo local de una emergencia.

\section{PACHACÚTEC Y LOS RECURSOS EN CASO DE UNA EMERGENCIA}

\section{1. Los recursos previstos}

El proyecto Sirad ubicó unos diez recursos necesarios en caso de emergencia: centros de decisión e intervención, abastecimiento de agua, atención médica, vialidad y transporte, telecomunicaciones, abastecimiento de alimentos, abastecimiento de energía, áreas potenciales de refugios, áreas potenciales de escombros. No fueron considerados todos los elementos, sino los más esenciales a escala metropolitana.

Pachacútec está alejado de la mayoría de ellos, por estar lejos de los centros de mando de la aglomeración y de la parte más consolidada y rica de la ciudad. Este difícil acceso empeora con los recursos específicos como lo son los hospitales de campaña o las brigadas de rescatistas (fig. 7).

Por lo tanto, un corte en las dos carreteras de acceso a Pachacútec, o la caída de puentes sobre los ríos Rimac y Chillón, aislaría aún más la aglomeración de estos recursos. Más allá del acceso físico, se puede suponer seriamente que estos recursos servirán prioritariamente para las poblaciones aledañas y otras zonas tal vez más afectadas porque son mayormente densas y pobladas o de mayor interés. Es la razón por la cual, durante las primeras horas de ocurrido un desastre, hay que pensar en las propias capacidades que tiene Pachacútec y que, por ser una zona marginada, ha desarollado para el uso cotidiano.

Entre ellas existen los servicios semejantes a los que vimos a escala metropolitana, pero de menor escala. Nuevo Pachacútec cuenta con tres centros de salud: el centro materno infantil Perú-Corea con atención las 24 horas, y los centros «3 de Febrero» y «Bahía Blanca» abiertos solo de día (12 horas). Sus capacidades de atención son limitadas pues entre los tres cuentan con menos de 10 camas. Para la población y las organizaciones sociales de base, estos centros representan hitos para ubicarse y uno de los lugares adonde acudir en caso de emergencia. Como brigadas de intervención existen el personal de la comisaría (44 policías asignados14) y las patrullas móviles del serenazgo (6 a 8 serenos que estacionan en los asentamientos aledaños a Nuevo Pachacútec). La comisaría cuenta con 5 camionetas $y$, elemento original a subrayar, 5 caballos. Las condiciones del terreno, que impiden el uso de las camionetas en las zonas de pendiente y demasiado arenosas explica este modo de movilizarse. La otra razón tiene que ver con el control territorial: la policía montada puede intervenir con mayor eficacia frente a barras de fútbol, protestas, invasiones de terrenos y peleas de pandilleros. El serenazgo cuenta con 6 camionetas y tiene también su modo particular de movilizarse: las cuatrimotos para subir a los arenales. Cuentan con radios. Ahora

14 Esta cifra incluye a los policías aunsentes por caso de enfermedad, vacaciones y capacitación. 


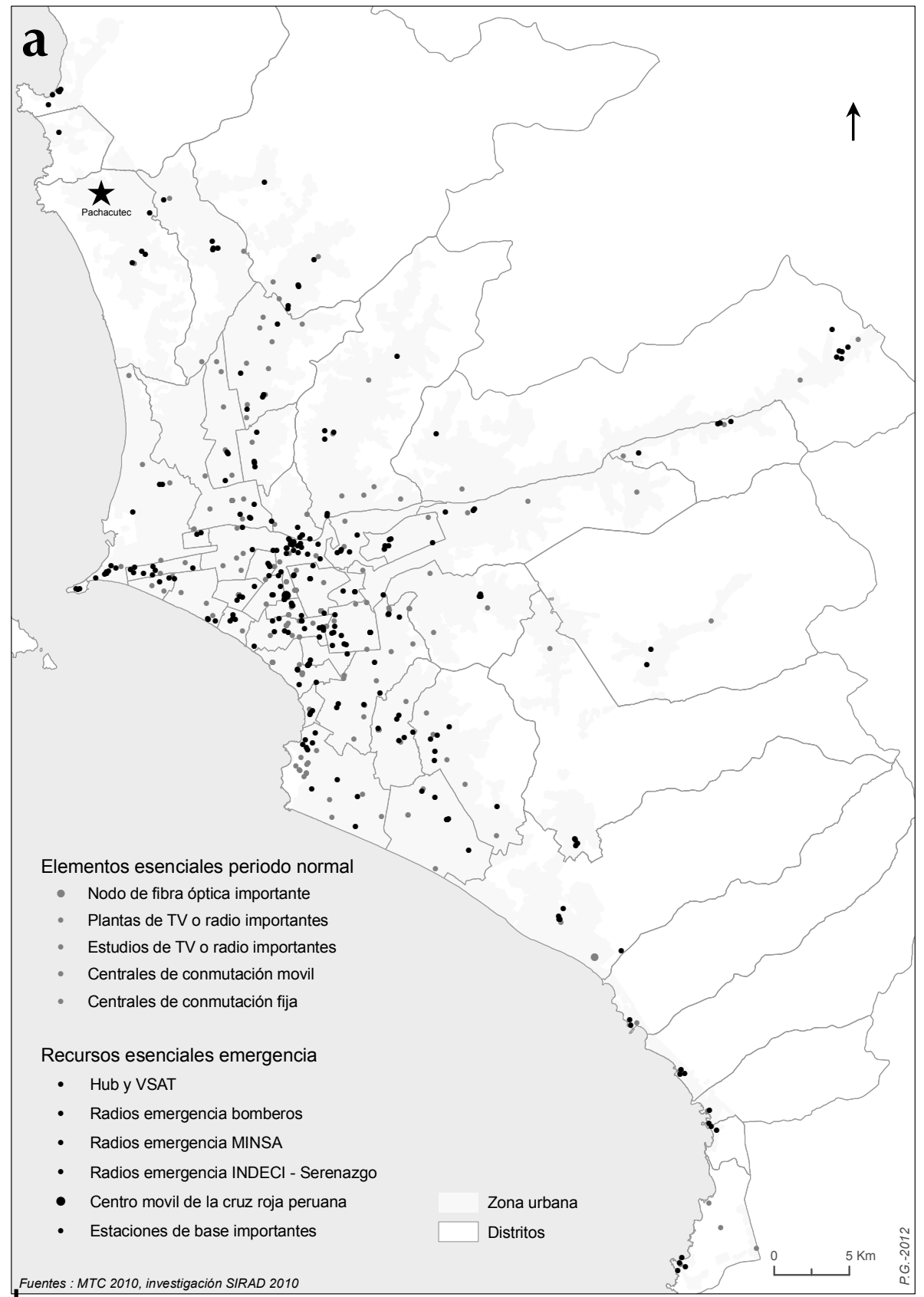

Figura 7 - Alejamiento de los recursos metropolitanos para la gestión de crisis

a: Recursos esenciales de telecomunicaciones para el manejo de emergencia 


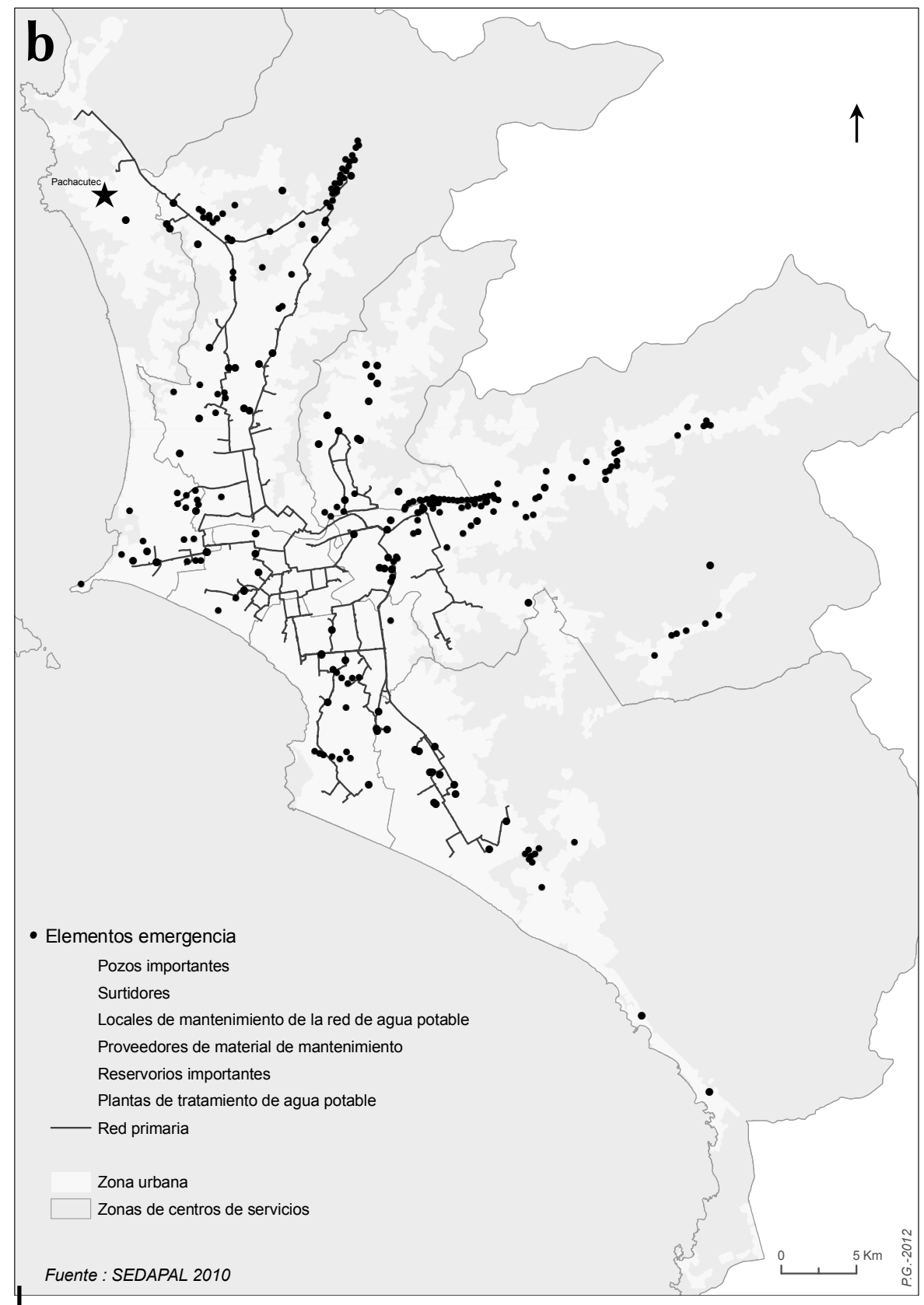

Figura 7 - Alejamiento de los recursos metropolitanos para la gestión de crisis

b: Recursos esenciales del abastecimiento de agua para el manejo de emergencia 


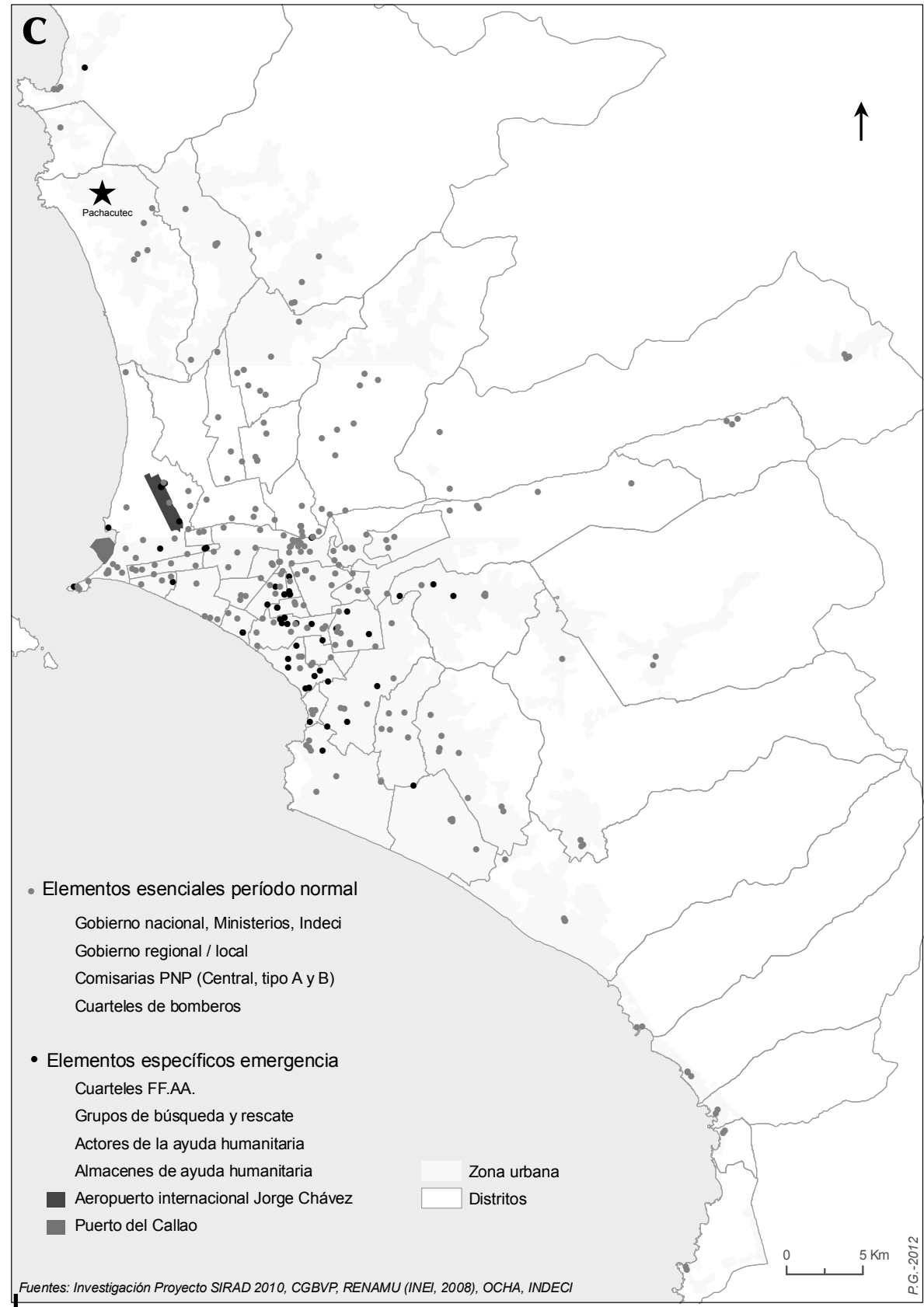

Figura 7 - Alejamiento de los recursos metropolitanos para la gestión de crisis

c: Recursos esenciales de decisión e intervención para el manejo de emergencia 
Las periferias, ¿territorios de incertidumbre? El caso de Pachacútec, Lima-Callao, Perú

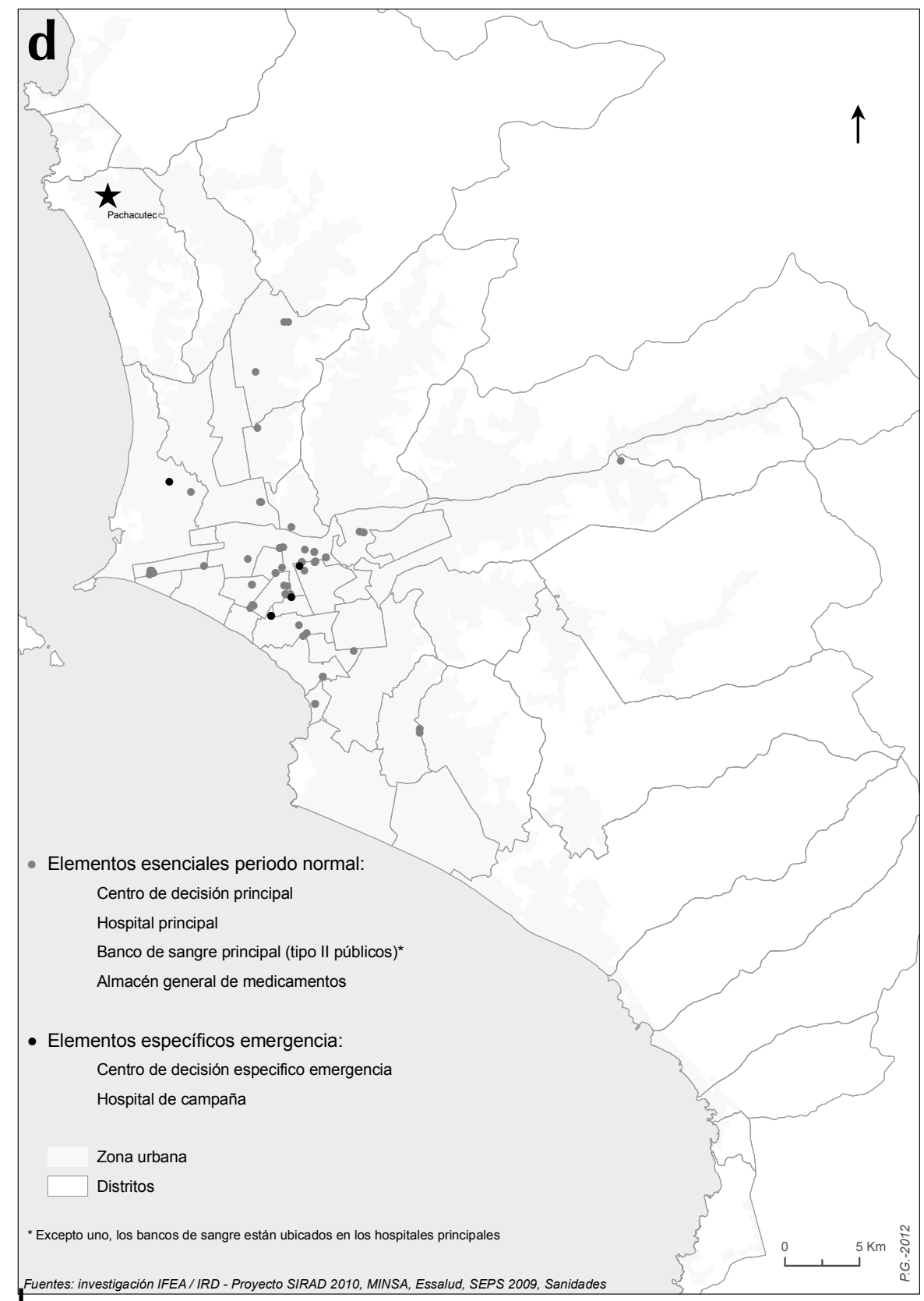

Figura 7 - Alejamiento de los recursos metropolitanos para la gestión de crisis

d: Recursos esenciales de la atención médica para el manejo de emergencia 
bien, estas cerca de cincuenta personas deben atender la totalidad de Pachacútec, o sea 250000 habitantes y más de 500 ha. Esta simple comparación numérica muestra que se necesitan otros grupos de intervención y otros modos de movilizarse y de comunicar para manejar una emergencia.

\section{2. Los recursos no previstos e informales}

El trabajo de campo nos permitió identificar tres recursos específicos de Pachacútec, recursos del funcionamento normal pero con posibilidades de servir en caso de emergencia. Son los mototaxis para el transporte, los altavoces para la comunicación y el cementerio informal para el manejo de los cadáveres (fig. 8). Los tres incluyen un grado de informalidad más o menos fuerte. Si la presencia de altavoces y de un cementerio son informales, la actividad de los mototaxistas es en parte formalizada.
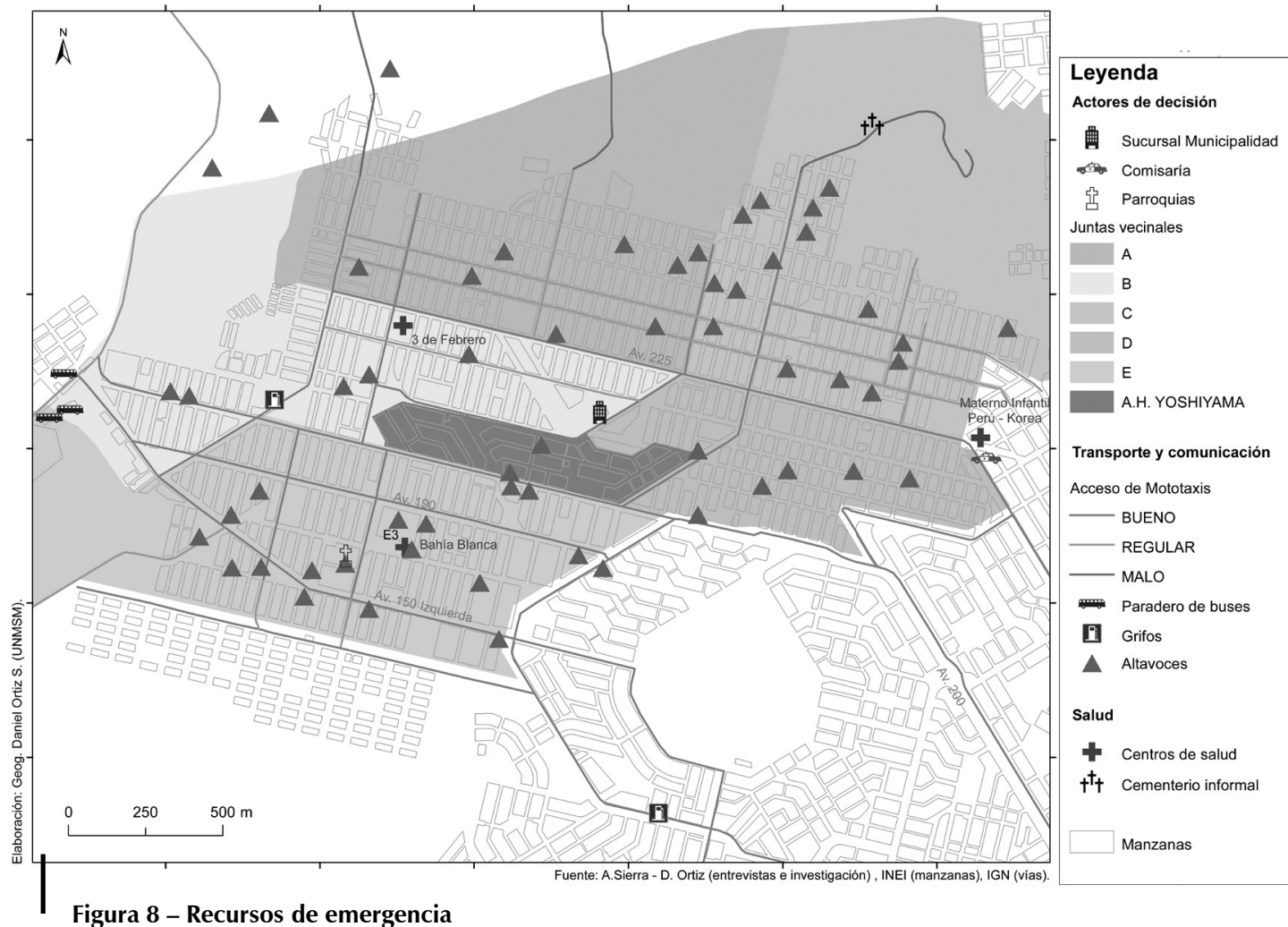

Figura 8 - Recursos de emergencia 


\section{2. 1. Un grupo a capacitar: los mototaxistas}

Este modo de transporte es un medio de trabajo surgido de la necesidad de empleo y las necesidades de transporte dentro de un barrio o una comunidad. Circulan en Pachacútec unos 1400 mototaxis. Sirven para dezplazarse dentro del poblado, y pocas veces salen de él. De manera excepcional van hasta el centro de Ventanilla. Su uso es muy común para alcanzar los puntos de interés (colegios, mercados, terminal de transporte, antena municipal, centros de salud, comisaría). Por lo tanto, sus rutas siguen por lo general las calles principales.

La hipótesis formulada es que pueden ser un recurso de emergencia por varias razones:

- Son muchos y cada uno podría llevar medicamentos, pequeñas herramientas, un herido.

- Es un medio ágil de transporte, manejable por varias personas, incluso sin licencia de conducir, adaptado al terreno ya que pueden usar vías que no utilizan los otros medios de transporte. Sin embargo, las pendientes más fuertes, como las vías de arena, son un obstáculo y los mototaxis pueden volcarse fácilmente.

- Una vez lleno el tanque de gasolina, tienen una autonomía de 1 a 2 días, dependiendo de las carreras. Por lo tanto pueden ser un recurso en la espera de modos de transportes masivos. El recurso funciona gracias a otro recurso, el de las gasolineras, sabiendo que existen 6 de las cuales 4 son informales.

- Tienen un conocimiento bastante bueno del territorio aunque tendremos algunos matices al respecto, por la razón expuesta anteriormente de que recorren usualmente las mismas rutas.

- Están organizados en asociaciones y empresas lo que significa que pueden tener talleres de capacitación para situaciones de emergencia y tener una organización colectiva para enfrentar este momento.

Las entrevistas realizadas muestran que ellos están dispuestos a recibir una capacitación pero tanto, si no más, para saber enfrentar las violencias que para enfrentar las consecuencias de un desastre. Todos los entrevistados consideran positivo el hecho de ser un recurso en caso de emergencia. Hay que subrayar que tienen ya un funcionamento autónomo pero que provoca cierta distancia con la población. Más allá de que, generalmente, tienen mala fama en Lima15, ellos solo confían en ellos mismos en caso de incidente. En las asociaciones y empresas tienen su propio seguro (el SOAT). Si uno de ellos es asaltado o tiene un accidente, primero trata de llamar a sus colegas y no a la policía o a los vecinos. Otro síntoma de esta desconfianza, es que cuando pueden van a buscar su gasolina a Puente Piedra porque la consideran de mejor calidad que en Pachacútec. En fin,

${ }^{15}$ Los mototaxis son generalmente criticados por ser inseguros y contaminantes. Simbolizan la pobreza y la informalidad aunque estén registrados. Muchos de ellos son pandilleros o ex pandilleros como se identificó en otras zonas de Lima. Toman este trabajo por estar desocupados y no encontrar otra alternativa. Todas estas imágenes hacen que las municipalidades les prohíben circular en muchas partes de la ciudad. 
su actividad está en parte formalizada; hasta se podría hablar de una informalidad formalizada, ya que los mototaxistas como servicio público de transporte no estaban contemplados dentro de los planes municipales o de transporte pero que luego la municipalidad empezó a interesarse y empadronarlos.

Sí pueden responder a cierta incertidumbre en caso de manejo de una emergencia, puesto que ellos viven varias incertidumbres que valen tanto en este caso como en lo cotidiano. Estas incertidumbres se deben a:

- Su vulnerabilidad frente a las violencias.

- Su imagen y el riesgo de limitar sus actividades.

- Los obstáculos que pueden existir en las vías y la posibilidad de volcarse.

\section{2. 2. Altavoces para alertar y comunicar}

Hemos censado por lo menos 60 altavoces llamados localmente «perifoneos». Permiten cubrir el territorio de Nuevo Pachacútec, aunque la cobertura es más escasa en las vertientes. Son de uso cotidiano para enviar anuncios. Generalmente, tienen un propósito comercial lo que explica su presencia en cada mercado. Muchos dirigentes vecinales poseen uno para facilitar las convocatorias a reuniones o informar de eventos especiales. Las encuestas muestran que toda la población está atenta a este medio de comunicación considerado como el más común para tener noticias del barrio. Los pobladores nos indicaron que usan el altavoz más cercano para organizar acciones solidarias después de un accidente como el del incendio de una casa. Este medio de comunicación, aunque muy común y conocido, es totalmente informal. No forma parte de una red sino que cada cual lo instala a su conveniencia. Es una de las razones por la que no son bien percibidos por las autoridades. Un antiguo comisario de policía del sector nos indicó que los altavoces afectan el medio ambiente, argumento que cayó tras una realidad que reveló él mismo: los «perifoneos» sirven también para avisar que la policía llega, lo que confirma que es un buen sistema de alerta. A pesar de esta informalidad o de su rechazo por parte de algunas autoridades, representan una oportunidad en caso de emergencia:

- como sistema de alerta,

- para organizar los socorros o

- para ayudar a la recuperación temprana.

Actualmente las incertidumbres en torno a este recurso radican en el abasto de energía y en el manejo individualizado. Una alimentación eléctrica autónoma y la puesta en red de los altavoces resultan necesarios para implementar este recurso.

\section{2. 3. La problemática de los cuerpos de fallecidos}

El cementerio legal de Pachacútec es el de Puente Piedra a 9 kilómetros. La planificación elaborada a inicio del milenio tenía previsto un lugar para un cementerio, pero nunca se acondicionó. Sin embargo, en gran parte por razones 
económicas, el terreno fue tomado por la población para enterrar sus muertos sin que existan las normas sanitarias y urbanísticas para ello (fig. 9).

Un desastre de gran magnitud como un sismo con sus consecuencias (en particular los incendios) provoca la muerte repentina de numerosas personas. Con la debilidad de las capacidades sanitarias y las condiciones ambientales (fuerte humedad todo el año y fuerte calor en verano) es necesario enterrar rápidamente los cadáveres. Los terrenos existen ya con esa función, con acceso y son conocidos por la población. Viendo las respuestas de la población, este cementerio informal seguirá funcionando y será de todos modos la alternativa en caso de emergencia y, por lo tanto, tendría que ser considerado por la población. La incertidumbre actual radica en posibles invasiones de terrenos por parte de nuevos pobladores.

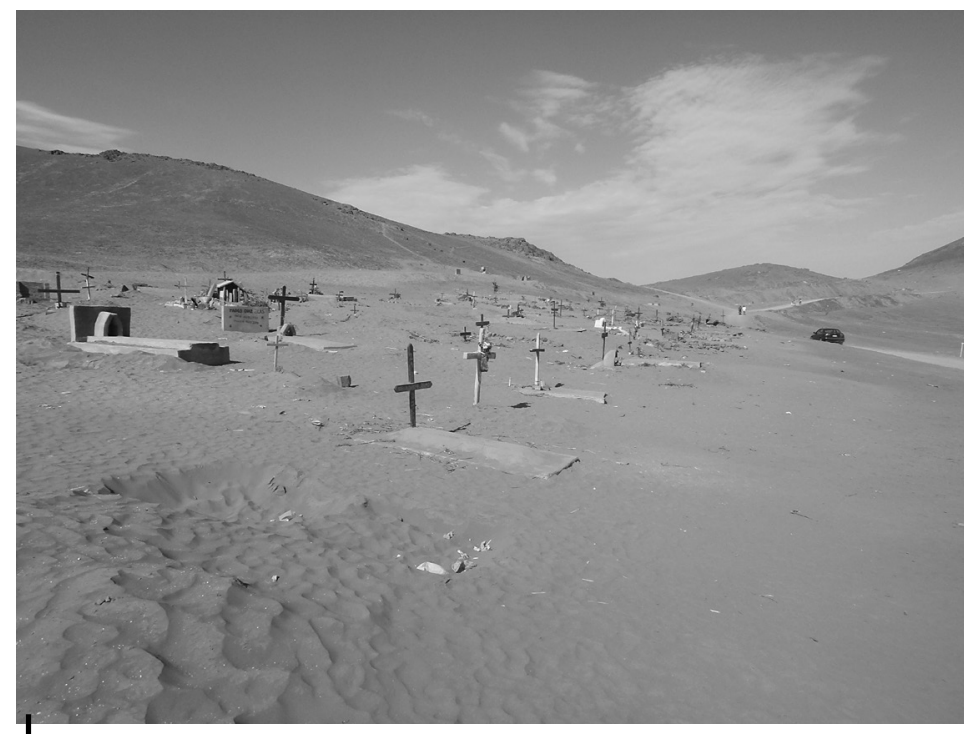

Figura 9 - Cementerio informal utilizado por habitantes de Pachacútec

\section{3. Las organizaciones sociales y vecinales}

Detrás de este término hay un amplio abanico de actores colectivos. Las organizaciones sociales abarcan:

- las organizaciones vinculadas a un programa social estatal como son los comedores populares autogestionarios (Pronaa) y los wawa wasi (Ministerio de la Mujer y poblaciones vulnerables16). En la misma categoría se encuentran las organizaciones definidas por la ley, con apoyo del gobierno central, pero

\footnotetext{
16 Hasta 2011, Mimdes, ministerio de la Mujer y Desarollo Social.
} 
vinculadas a los gobiernos locales como lo son los comités de Vaso de leche y los clubes de Madres. Son conocidas como las organizaciones sociales de base (OSB) inscritas en el Registro Público;

- las organizaciones vinculadas a las iglesias y en particular a la parroquia entre las cuales existen también comedores populares o servicios de salud;

- organizaciones vecinales y fundamentalmente las juntas directivas y los comités de seguridad ciudadana;

- las asociaciones provinciales por región de origen y todas las asociaciones deportivas, culturales, etc.;

- los gremios de profesionales.

Las organizaciones sociales tienen un papel previsto en el Sistema Nacional de Defensa Civil y que fue reforzado con la última ley del 201117 que crea el SIstema NAcional de GEstión de Riesgo de Desastre (Sinagerd). Deben integrar los comités distritales de defensa civil (o de gestión de riesgo de desastre). Algunas de ellas tienen un papel previsto en caso de desastre. Tal es el caso de los wawa wasi. El programa de ayuda a los niños menores de 4 años tiene un componente para asuntos excepcionales, «wawa wasi temporal» como para las «familias con hijos menores de 47 meses, afectadas por situaciones de emergencia (friaje, deslizamientos, terremotos y otros desastres naturales)18》.

En Pachacútec, vimos que las organizaciones sociales de base (OSB) fueron el recurso de emergencia cuando se instalaron repentinamente miles de personas en aquellas pampas desiertas y desérticas. Frente a los primeros conflictos a fines de 2000, se formaron comités vecinales de seguridad ciudadana en coordinación con la Policía Nacional. Las organizaciones vecinales trabajan con ONG peruanas o internacionales desde ese mismo año. Coprodeli, ligado a la Iglesia Católica, creó los primeros módulos de educación. Varias organizaciones religiosas, en particular cristianos protestantes, han venido desarrollando sus actividades caritativas. A partir de 2001, la ONG Alternativa con financiamento alemán crea una infraestructura de abastecimiento de agua con tanques. Este es desde entonces administrado por comités vecinales de administración del agua potable (Covaap), otra organización clave. Con el transcurso de los años, nuevas ONG han intervenido y en la actualidad hay una decena que tiene presencia en esta periferia, muchas relacionadas a las cuestiones de la infancia, de los jóvenes y las familias como la muy presente Tierra de Niños.

En lo que son las OSB, Pachacútec cuenta hoy con más de veinte comedores populares, una quincena de wawa wasi, y aproximadamente cincuenta comités de vaso de leche. Estos últimos están vinculados a un comité central de 6 miembros que representan el estamento de Nuevo Pachacútec, reconocido y apoyado

17 Ley n. $^{\circ}$ 29664. 02/2011.

18 http://www.mimdes.gob.pe/files/PROGRAMAS\%20NACIONALES/PNWW/wawawasi_temporal_ ugds.pdf 
por la municipalidad de Ventanilla, en su gerencia de Participación vecinal. Los comedores populares son lugares clave, a veces integrados a los mercados. Fueron los primeros locales de organizaciones instalados después de la llegada de los pobladores. Se crearon con la ayuda del Pronaa y, como la mayoría de esas organizaciones, eran administrados por las mujeres, cada sector teniendo el suyo en su centro. Siguen siendo lugares en los que se difunden noticias y apoyo a candidatos, siendo utilizados por los gobiernos y los partidos a fines electoralistas. Como para los comités de vasos de leche, los comedores tienen una organización en red pues cuentan con un comité central de cinco miembros. Sin embargo, hoy en día, muchos comedores son de escasos recursos (fig. 10) y están sujetos al robo. En general, sus locales son precarios, de madera, vulnerables a los incendios.

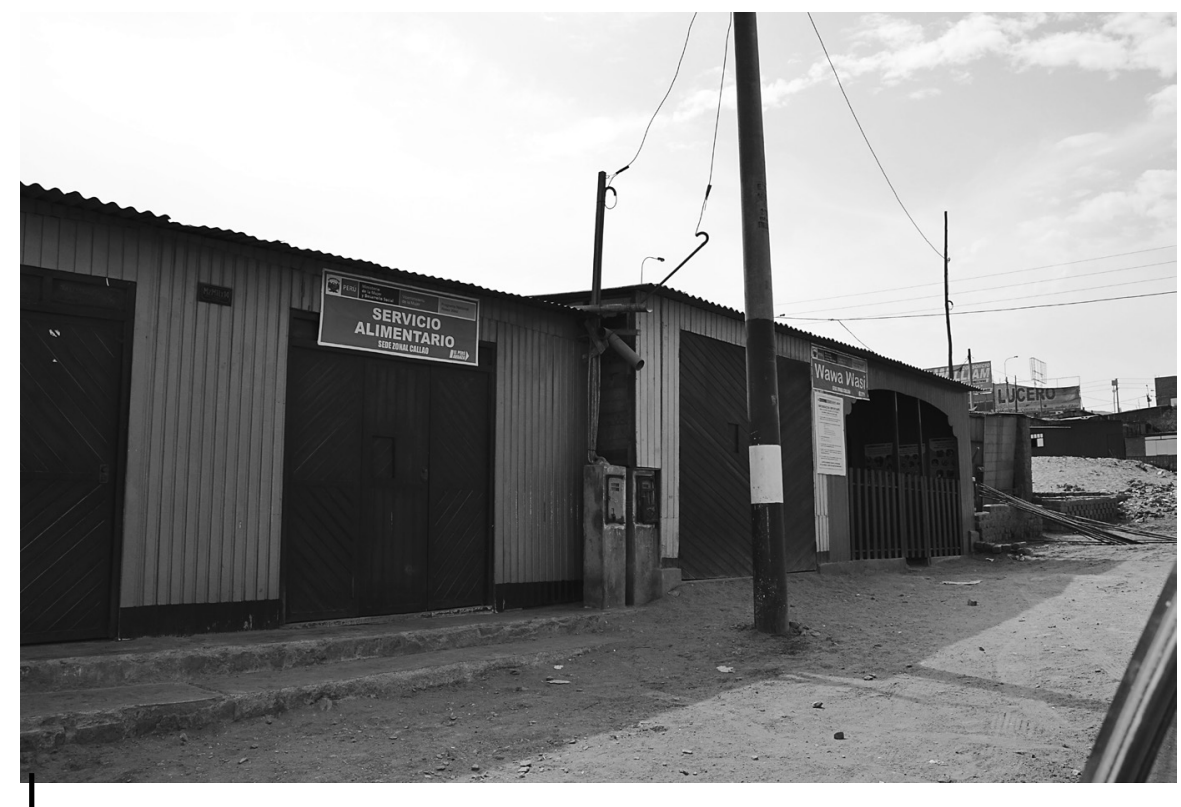

Figura 10 - Comedores comunitarios en Pachacútec

Nuevo Pachacútec, por haber sido poblado de gente procedente de varias partes del país, sigue teniendo asociaciones de provincianos. Estas permiten constituir redes útiles en caso de desastre. En otras ocasiones, como en Haití19, varios damnificados de la ciudad se refugiaron en casa de familiares en zonas no afectadas. También pueden ser una fuente de ayuda para la recuperación temprana y la reconstrucción.

Los dirigentes barriales notan un debilitamiento de las organisaciones colectivas quejándose de la falta de implicación de los vecinos cuando ya tienen los servicios.

${ }^{19}$ Estudio de vulnerabilidad de Tabarre, Porto-Principe, Haití. 
Nos faltan datos para averiguar esta percepción que puede generarse por la mayor implicación de los dirigentes, quienes quisieran más ayuda. Sin embargo, se pudo notar que la mobilización se hace generalmente a corto plazo cuando hay un pedido específico como problemas de títulos de propiedad o falta de servicios y equipamentos. Lo interesante es justamente ver cómo frente a una situación de crisis y al final de la incertidumbre debida a la precariedad y la marginalidad, las organizaciones sociales y vecinales son a la vez una respuesta y un medio para iniciar nuevas acciones.

La contraparte es la dificultad en tener una visión común a todo Pachacútec, siendo estos recursos un modo de enfrentar los problemas inmediatos. Otra vulnerabilidad, fuente de incertidumbre, radica en las divisiones entre vecinos, a veces por razones políticas, que provocan competencia entre organizaciones básicas como las juntas vecinales. Estas últimas son una organización básica. Ninguna de ellas ha trabajado el tema de los riesgos de desastre, pero siendo la organización que tiene más proximidad tanto con el conjunto de la población como con las diferentes autoridades y que, por lo general, los dirigentes poseen altavoces, la consideramos como un recurso fundamental en caso de emergencia. Como sus existencias dependen de la organización territorial, preferimos abordar el caso de estas juntas con el tema del control territorial.

\section{LAS INCERTIDUMBRES EN TORNO AL CONTROL TERRITORIAL}

El control territorial nos interesa directamente en el tema de gestión de riesgo y de crisis por las experiencias de pánico o de saqueos que han existido en caso de desastre. Se requiere la presencia de autoridades que organicen las diferentes etapas de la gestión de crisis y que aseguren un mínimo de orden público. Los diferentes talleres y las simulaciones de crisis a las cuales se pudo asistir en Lima (Sierra, 2012), indican un temor de ciertos lugares y de ciertas partes en cuanto al buen manejo de la situación. Los asentamientos periféricos pobres forman parte de un imaginario de desorden permanente que se agravaría en caso de desastre. Para nosotros, la incertidumbre en cuanto a la existencia y la forma del control territorial es un factor de vulnerabilidad. Por lo tanto es preciso aclarar lo que se entiende por tal concepto. El control territorial supone la existencia de dispositivos humanos e institucionales, reglamentarios que permitan conocer, organizar y modificar un territorio. Estos dispositivos requieren cierto grado de legitimidad y un mínimo de recursos para ejercerse.

\section{1. Fragmentación territorial y perspectiva distrital}

Los 30000 habitantes de Nuevo Pachacútec tienen una junta directiva, el comité ejecutivo central de la Ciudad Modelo Autogestionaria Pachacútec (CEC-CIMAP), registrada legalmente por la municipalidad del distrito de Ventanilla en 200320.

20 Resolución directorial n. ${ }^{\circ}$ 067-2003/MDV-DPV. 
Sin embargo, para impedir que se constituya un actor central con mayor fuerza, las autoridades lotizadoras favorecieron el estatus de las directivas sectoriales. Este proceso de fragmentación tiene similitudes con la organización del resto de Lima en la cual se fortaleció el poder de las municipalidades distritales disminuyendo la de la municipalidad provincial para limitar el poder del alcalde de Lima frente al gobierno nacional (Jaramillo \& Botero, 2010). Consecuentemente, el funcionamento del CEC-CIMAP se debilitó y por lo tanto la población reconoce primero a los representantes de los sectores. En efecto, Nuevo Pachacútec está dividido en cinco sectores (A, B, C, D, E) que, a su vez, están divididos en grupos residenciales (de A1 a A4 o de E1 a E6 por ejemplo). Cada sector tiene su junta directiva. Cada grupo residencial tiene su delegado. Por lo tanto, toda esta organización forma una red estrecha al interior del territorio que fue pensada en forma piramidal pero a la cual le falta una cabeza. Supuestamente, la municipalidad de Ventanilla está presente a través de su gerencia de participación vecinal, y su sucursal en Nuevo Pachacútec trata directa y separadamente con las 5 dirigencias de sectores. La percepción actual de que los funcionarios de la antena municipal no trabajan por todos y que la municipalidad de Ventanilla está alejada de las preocupaciones del pueblo, ha provocado la tentativa de renacimiento de la junta central y dado nuevo sustento al proyecto de crear un nuevo distrito con todo Pachacútec.

La distritalización del conjunto de Pachacútec es un asunto a tomar en cuenta porque se trata de nuevas formas de autonomía, la misma que es promovida en el caso de la gestión de las emergencias. Esta autonomía distrital está pensada desde muy temprano pues el plan de zonificación de Pachacútec contempla un amplio espacio central para acondicionar una plaza cívica donde estén las dependencias del futuro gobierno distrital. Este punto merece especial atención porque la base Sirad indica que es un espacio potencial para albergues en caso de emergencia, ya que en la actualidad se presenta como un terreno baldío de propiedad pública. Sin embargo, está previsto ordenarlo y construirlo en parte para que sea el símbolo político de la comunidad de vecinos. Aunque anecdótico, este ejemplo muestra la dificultad de pensar al mismo tiempo en el desarrollo urbano a largo plazo y la gestión de los espacios de emergencia. Por un lado, en caso de desastre se necesitan espacios libres para albergues, hospitales de campaña, remoción de escombros, organización de la ayuda humanitaria. Por otro lado, el desarollo urbano consume los espacios libres, sobre todo cuando se ubican en el centro de un poblado. Sin embargo, se puede notar que desde hace más de diez años, se ha respetado este terreno sin conocer invasiones lo que puede mostrar el reconocimiento del objetivo distrital. Los moradores no están todos de acuerdo con la creación del distrito de Pachacútec. Los unos por pragmatismo, porque simplemente no se han cumplido los requisitos de densidad poblacional, de equipamiento y servicios. Algunos por pensar que sería alejarse más del apoyo del conjunto de Ventanilla. Pero por muchos otros, hay que seguir ese objetivo. El sentimiento muy difundido es que la municipalidad de Ventanilla no se preocupa por Pachacútec y que los impuestos pagados en Pachacútec no sirven a su comunidad. Algunos líderes tienen la convicción que tenían los primeros pobladores, es decir que se puede crear en Pachacútec una ciudad modelo. Por eso se trata de desarrollar una identidad 
comunitaria, sustentada en su fundación épica, su lucha por la sobrevivencia, su enfrentamiento a las autoridades y medios aún precarios como la creación de un periódico local, Voces y Raíces de Pachacútec 21 . Lo que podemos ver, es que el actual alejamiento tanto físico como social de Pachacútec genera ya ciertas formas de autonomía y autogestión con respecto al resto de la ciudad: antena municipal, servicios privados e informales, actividades económicas con instalación de talleres, recursos alternos informales como indicados anteriormente. O esta autonomía se consolida con nuevos servicios y equipamientos, con presencia de autoridades electas reconocidas y fuertes y genera una autonomía real, o se añade una autonomía política sin nuevos medios, y el riesgo para Pachacútec es de encontrarse bajo un problema mayor de control territorial.

En el caso de Pachacútec, quienes tienen el control teórico del territorio son el distrito de Ventanilla y la Región Callao. El Estado está presente a través de la policía y de algunos servicios (unidades educativas) y empresas (Sedapal). Sin embargo, la presencia de cada una de estas instituciones es débil, con recursos limitados. Por tal razón, las directivas electas de cada sector y las organizaciones sociales de base tienen su rol en este control, difundiendo normas y prácticas, siendo puntos de encuentro de la población con cierto poder de convocatoria. Por ser las más cercanas a la población, estas organizaciones tendrían un papel mayor en la organización de la primera respuesta frente a una emergencia. Pero, una incertidumbre mayor en caso de emergencia radica en el poder que pueden tener ciertos grupos delincuentes e incluso criminales.

\section{2. Pachacútec, ¿territorio de riesgo, territorio inseguro, territorio incierto?}

Antes de ser percibido como un territorio de riesgo de desastre, Nuevo Pachacútec es considerado como un territorio inseguro. Todas las encuestas lo ponen como el primer problema tanto para las casas como para las actividades que ejercen algunos como es el caso de los mototaxistas y de los transportistas. Esta inseguridad califica de forma diferente los cinco sectores y sus extensiones, generando una geografía compleja (fig. 11).

Los asentamientos humanos, invasiones recién construidas, hogares de informalidad y de ilegalidad, son lugares desconocidos por el resto de la población con mala fama (Protzel, 2011). Los mototaxis evitan ir hacia allá y no solo por la arena. La policía trata de vigilar esas extensiones pero sin logros: llegan demasiado tarde cuando se desarrolla una invasión y no siempre tienen pruebas para denunciar la existencia de tal invasión.

Respecto a los cinco sectores, son el sector A y E los que tienen más inseguridad. De cierto modo, son dos periferias dentro de Nuevo Pachacútec pues los sectores

21 Creado en 2011, este periódico tiene al momento de escribir estas líneas alguna dificultad a perdurar. 


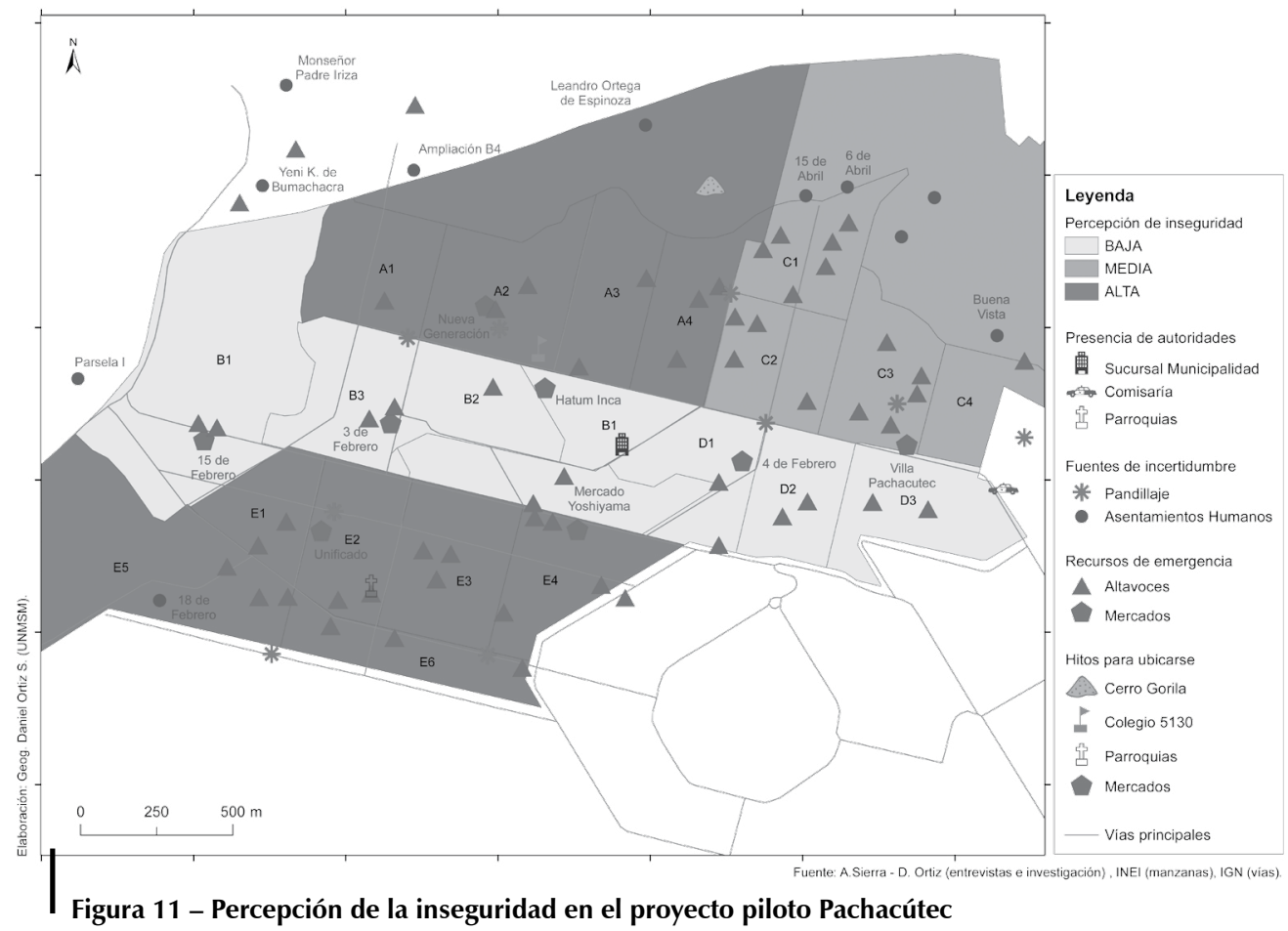

D y B son los más consolidados, equipados y los que tienen los servicios y actores centrales (comisaría, antena municipal, eje comercial).

Las fuentes de inseguridad son múltiples. Se cuenta con robos particularmente fáciles por la precariedad de las viviendas y la posibilidad de pasar por debajo de las rejas cabando en la arena. Un problema mayor que destacan las organizaciones sociales son las violencias domésticas, generalmente en contra de las mujeres y los niños. Estos acontecimientos frecuentes crean una inseguridad permanente. Pero lo que temen de forma general los moradores son los pandilleros. Estos crean peleas y enfrentamientos particularmente violentos, muchas veces cerca de los colegios y de los mercados. Las encuestas y entrevistas permitieron identificar unos cuantos puntos críticos. La existencia y el reconocimiento de tales puntos críticos tienen consecuencias sobre las prácticas cotidianas, provocando desvíos. Más que las peleas, es el uso y manipulación de armas de fuego por parte de las pandillas, lo que genera mayor preocupación. Básicamente, las pandillas son grupos de jóvenes que se enfrentan (fig. 12). Pueden ser cincuenta de ambas partes como lo recuerda la dirigente del mercado Unificado quien vio esta multitud frente a la cual los dos únicos agentes del serenazgo presentes no podían hacer nada. Las balas perdidas pueden herir a transeúntes y a los mototaxistas quienes temen particularmente a los pandilleros. Ellos están también metidos en las redes del tráfico de drogas por lo que ocupan chozas abandonadas o 


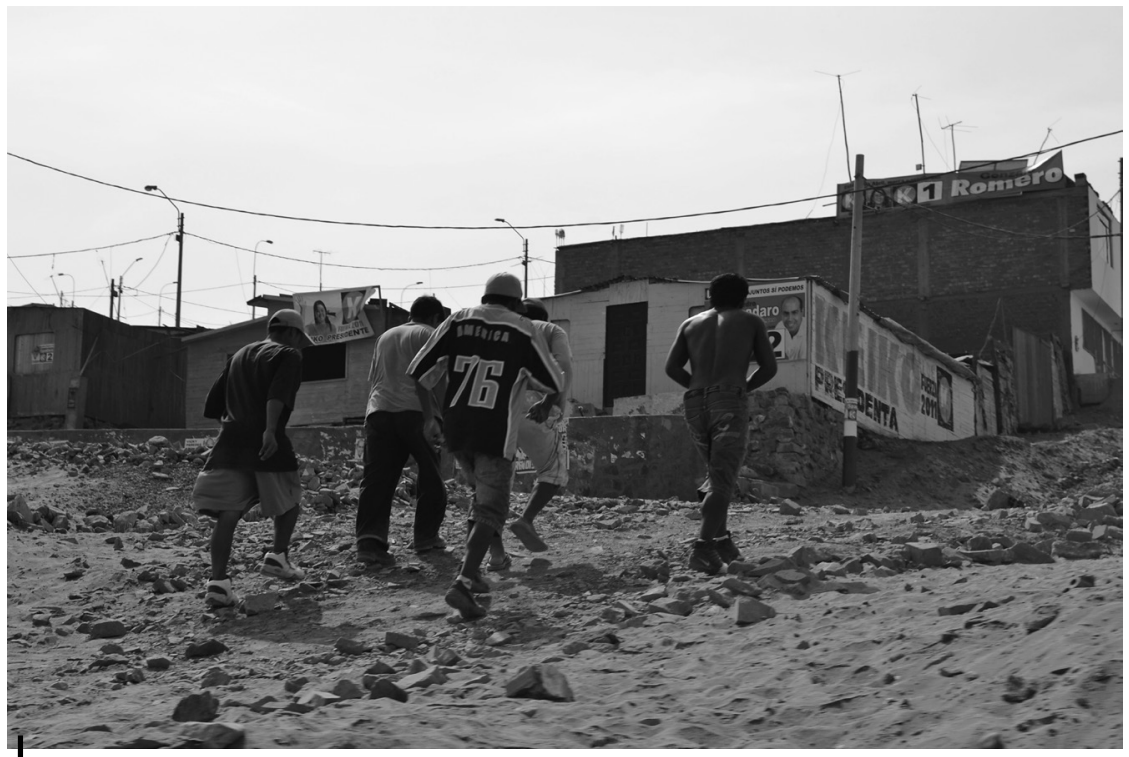

Figura 12 - Grupo de jóvenes pertenecientes a una pandilla

desalojadas. Su objetivo favorito son los más jovenes, y es otra razón por la cual están muy presentes al costado de los colegios. Todos los testimonios concuerdan en decir que los pandilleros son contratados para acciones delictivas e incluso criminales. El actor clave es constituido por los constructores civiles locales. Estos se organizan en seudogremios, sindicatos no necesariamente reconocidos y fuera de la cooperación de constructores civiles (Capeco). Las directivas tienen vínculos estrechos con exreclusos, lo que no es un problema en sí pues la ley pide que las empresas contraten exreclusos para inclusión social, pero que muestra la proximidad entre ciertos constructores y el mundo de la delincuencia y de los penales. Esos seudogremios cobran cupos para cada obra. Para no tener la competencia de los constructores de otros lugares y para desarrollar actividades sobre nuevos terrenos, amenazan, desalojan obras, provocan incendios. Para realizar estas tareas contratan a pandilleros quienes no solo poseen cuchillos sino también armas de fuego. Por esa razón, y como lo comprobamos con distintas entrevistas, los pandilleros son también contratados por agentes privados de seguridad quienes necesitan mano de obra para hacer de guardaespaldas. Esta alianza objetiva entre los constructores civiles, los pandilleros, los traficantes de droga, los traficantes de tierra y agentes de seguridad fundamenta la existencia de una posible alternativa en el control territorial de Pachacútec. Frente a ello, la policía tiene una actitud ambigua. Sus medios son limitados y se sospecha que en muchos casos cierran los ojos o prefieren no enfrentarse y dialogar con los constructores civiles por ejemplo. Tratan de trabajar con la población apoyando a juntas vecinales de seguridad ciudadana y haciendo rondas comunes. La comisaría cuenta con un encargado o una encargada de participación vecinal. Según la 
policía, el sector D, el más cercano a la comisaría, es el más organizado y participa en esta acción. Desde el inicio del poblado, la población estuvo preocupada por la inseguridad y trató de organizar una seguridad ciudadana. Muchos intentos fracasaron por falta de voluntarios y las presiones de los grupos delincuentes. En la actualidad, solo el sector $\mathrm{C}$ parece haber constituido un comité de vigilancia para combatir los robos. De semejante manera, los comerciantes del mercado Unificado hacen turnos de vigilancia por la noche, armados de matracas.

Para los pobladores, esta inseguridad es una fuente de incertidumbre cotidiana que para la problemática del riesgo de desastre se traduce en una fuerte vulnerabilidad. La presencia de delincuentes de diferente índole provoca una desconfianza generalizada poco propicia al desarrollo de acciones comunes entre vecinos.

\section{3. La incertidumbre vinculada al riesgo de desastre}

A diferencia de los discursos vinculados muchas veces por las autoridades y una parte de la población, los peligros naturales y tecnológicos no son desconocidos por la población, sino que forman un problema menor al de la delincuencia. Así, los moradores son muy conscientes de la vulnerabilidad que representan sus casas frente a incendios. Es el primer peligro indicado. La presencia de una mayoría de casas de madera y estera, las conexiones de cables eléctricos, el uso de combustibles y la presencia de talleres son factores de vulnerabilidad frente a tal peligro. Lo interesante es la ausencia de la mención de peligros naturales en una encuesta realizada sobre Nuevo Pachacútec en 2004. Ellos aparecen en una encuesta de 2008, que cabe decir fue relanzada en el marco de un programa de lucha contra el riesgo de desastre. Lo que nos sorprendió en las entrevistas es el gran temor que existe frente a un posible tsunami22, cuando ninguna ola puede llegar a las alturas de Nuevo Pachacútec. La existencia de este riesgo es mencionada por lo general por los que tienen vista directa al mar (fig. 13). Gracias a las entrevistas, se pudo identificar que Defensa Civil de Ventanilla divulgó información al respecto y que la mención de un peligro de tsunami se obtuvo también por los medios de comunicación, que desde inicios de 2010 difunden el hecho de que Lima/Callao puede sufrir sismos y tsunamis de gran magnitud. Es un ejemplo muy interesante de desarrollo de la percepción de un peligro que no existe objetivamente pero que sí añade a la angustia vivida por la acción informativa que a veces se hace de maneracatastrofista. De todos modos, tomando en cuenta que el riesgo es la posibilidad de perder algo o de no conseguir algo (Sierra, 2009), estos riesgos vinculados a peligros naturales, vienen en segunda posición muy atrás de los riesgos vinculados a la falta de empleo y la delincuencia.

En este contexto, la incertidumbre que vive la población con respecto a sus propias capacidades y a la capacidad de actuar de los grupos de delincuentes, se transforma en vulnerabilidad frente a un riesgo de desastre y en incertidumbre sobre el manejo

22 No hicimos una encuesta sistemática al respecto, pero la ONG COOPI en 2010 identificó que era el tercer peligro mencionado después de los incendios y de los terremotos. 


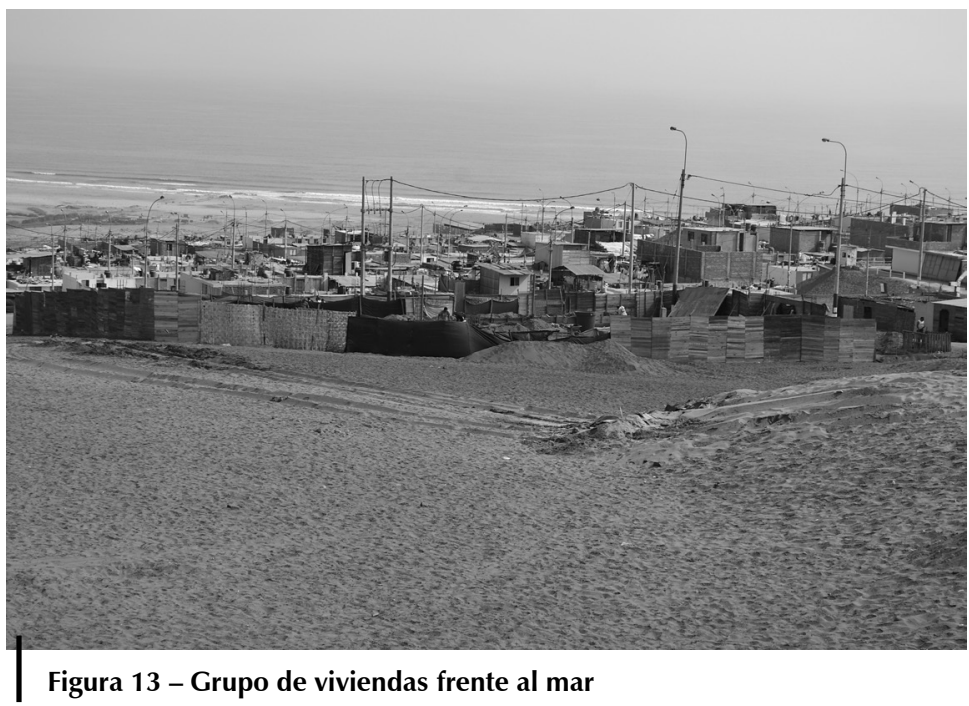

de la emergencia. Un desastre de gran magnitud que aisle a Pachacútec podría tener como consecuencias desorganizar más la comunidad y reforzar el papel de los grupos armados. De este modo existe una gran incertidumbre en cuanto al orden público en el caso de una crisis mayor. En ausencia de autoridades públicas, ¿cómo actuarían estos grupos? ¿Qué consecuencias tendría para el periodo posdesastre?

\section{CONCLUSIÓN}

La población de Nuevo Pachacútec vive un cotidiano hecho de incertidumbre. Esta última representa un factor de vulnerabilidad en cuanto se trata de riesgo. Frente a estas incertidumbres, la población ha desarrollado varios tipos de organización y recursos, incluso informales, que tienden a desarrollar una autonomía de esta periferia. Lo interesante es que tal autonomía es promovida por las instancias nacionales o internacionales que promueven la lucha contra los riesgos de desastres. En efecto, la autonomía permite enfrentar situaciones de emergencia que por su naturaleza misma deben ser tratadas primero por los actores locales.

La pregunta siguiente es saber qué tipo de autonomía se está desarrollando. Se podría incrementar la autonomía reforzando recursos que no existen, con mayor presencia de servicios públicos de la región o del Estado, es decir por parte de una de las autoridades constitucionales.

Sin embargo, aquí vemos que la autonomía se desarrolla más a cargo de organizaciones locales con ayuda de ONG y de programas sociales, pero sin mayor presencia de autoridades públicas. En este sentido, la autonomía puede convertir una periferia marginada en territorio bajo control de actores delincuenciales. Por 
tal razón, la lucha contra el riesgo de origen natural tiene que tomar en cuenta las distintas formas y fuentes de incertidumbre que se dan en un periodo normal y no solo generar nuevas incertidumbres a las cuales no se puede hacer frente debido a la falta de recursos.

\section{Agradecimientos}

Los autores agradecen infinitamente a la Sra. Luz Vallejo, vecina de Pachacútec, por su apoyo decisivo durante nuestro trabajo de campo, habernos facilitado ahí contactos numerosos y por acompañarnos a lo largo de esta investigación.

\section{Referencias citadas}

CARAMUTTI, R., 2004 - Tu espacio te da seguridad y nadie te la quita, Informe para CLASPO II - Estudio de Caso de Vivienda en el Cono Norte - Distrito de Ventanilla en las zonas de Nuevo Pachacútec y el Centro Poblado Menor Mi Perú, Alternativa, junio 2004.

CIMAD, 2005 - Nuevo Pachacútec, Oasis de esperanza, plan de desarrollo estratégico al 2010, 150 pp.; Lima: Alternativa.

D'ERCOLE, R. \& METZGER, P., 2009 - Las dimensiones espaciales del manejo de crisis. Interés de la investigación y aplicación en Quito. Bulletin de I'Institut Français d'Études Andines, 38 (3): 893-915.

DOLFUSS, O., 1997 - La mondialisation; París: Les Presses de Sciences Po.

GHORRA-GOBIN, C. (ed.), 2006 - Dictionnaire des mondialisations, 398 pp.; París: Armand Colin.

JARAMILLO JASSIR, M. \& BOTERO, M. H., 2010 - Descentralización en Lima: democracia local versus efectividad administrativa. Un modelo inacabado de descentralización, 52 pp.; Bogotá: Editorial Universidad del Rosario, Facultades de Ciencia Política y Gobierno y de Relaciones Internacionales, Universidad Colegio Mayor de Nuestra Señora del Rosario.

MATOS MAR, J., 2012 - Perú, Estado desbordado y sociedad nacional emergente, 573 pp.; Lima: Universidad Ricardo Palma editorial.

PROTZEL, J., 2011 - Lima Imaginada, 446 pp.; Lima, Perú: Fondo Editorial - Universidad de Lima. Proyecto: Culturas urbanas en America Latina y España desde sus imaginarios sociales.

ROJO, G., 2010 - Saqueos. In: El terremoto social del Bicentenario (S. Aguilera, ed.); Santiago de Chile: LOM Ediciones.

SIERRA, A., 2000 - Gestion et enjeux des espaces urbains à risque d'origine naturelle : les versants et les quebradas de Quito, Équateur; París: Université de Paris 8. Tesis de doctorado.

SIERRA, A., 2009 - Espaces à risque et marges : méthodes d'approche des vulnérabilités urbaines à Lima et Quito. Cybergeo: European Journal of Geography [en ligne], Vulnérabilités urbaines au sud. http://cybergeo.revues.org/22232 
SIERRA, A., 2012 - Simulaciones de crisis y vulnerabilidad urbana: el caso de la simulación nacional del 27 de noviembre del 2011 en Lima-Callao. Informe al INDECI (15 de marzo).

SIERRA, A. \& TADIÉ, J. (eds.), 2008 - La ville face à ses marges. Autrepart, n. ${ }^{\circ}$ 45: 216 pp.; París: IRD-Colin.

SIRAD, 2011 - Instituto Nacional de Defensa Civil (INDECI); Programa de las Naciones Unidas para el Desarrollo (PNUD). (2011a). Estudio SIRAD, Recursos de respuesta inmediata y de recuperacion temprana ante la ocurrencia de un sismo y/o tsunami en Lima metropolitana y Callao; Lima, Perú: INDECI / PNUD. 